\title{
Nitric oxide from inflammatory origin impairs neural stem cell proliferation by inhibiting epidermal growth factor receptor signaling
}

\author{
Bruno P. Carreira ${ }^{1}$, Maria I. Morte ${ }^{1}$, Ana I. Santos ${ }^{1,2,3}$, Ana S. Lourenço ${ }^{1,2,3}$, António F. Ambrósio ${ }^{1,4}$, \\ Caetana M. Carvalho ${ }^{1}$ and Inês M. Araújo ${ }^{2,3}$ *
}

${ }^{1}$ Centre for Neuroscience and Cell Biology, University of Coimbra, Coimbra, Portugal

${ }^{2}$ Regenerative Medicine Program, Department of Biomedical Sciences and Medicine, University of Algarve, Faro, Portugal

${ }^{3}$ Centre for Molecular and Structural Biomedicine, CBME/IBB, University of Algarve, Faro, Portugal

${ }^{4}$ Centre of Ophthalmology and Vision Sciences, Institute for Biomedical Imaging and Life Sciences (IBILI), Faculty of Medicine, University of Coimbra, Coimbra, Portugal

\section{Edited by:}

Lawrence Rajendran, University of Zurich, Switzerland

\section{Reviewed by:}

Marco Bacigaluppi, Università Vita-Salute San Raffaele, Italy Maria Vittoria Podda, Università Cattolica del Sacro Cuore, Italy

\section{*Correspondence:}

Inês M. Araújo, Regenerative

Medicine Program, Department of Biomedical Sciences and Medicine, University of Algarve, Gambelas Campus, Building 7, 3rd Floor, 8005-139 Faro, Portugal e-mail:imaraujo@ualg.pt
Neuroinflammation is characterized by activation of microglial cells, followed by production of nitric oxide (NO), which may have different outcomes on neurogenesis, favoring or inhibiting this process. In the present study, we investigated how the inflammatory mediator NO can affect proliferation of neural stem cells (NSCs), and explored possible mechanisms underlying this effect. We investigated which mechanisms are involved in the regulation of NSC proliferation following treatment with an inflammatory stimulus (lipopolysaccharide plus IFN- $\gamma$ ), using a culture system of subventricular zone (SVZ)-derived NSCs mixed with microglia cells obtained from wild-type mice (iNOS ${ }^{+/+}$) or from iNOS knockout mice (iNOS ${ }^{-/-}$). We found an impairment of NSC cell proliferation in iNOS ${ }^{+/+}$ mixed cultures, which was not observed in $\mathrm{NOS}^{-/-}$mixed cultures. Furthermore, the increased release of $\mathrm{NO}$ by activated $\mathrm{NOS}^{+/+}$microglial cells decreased the activation of the ERK/MAPK signaling pathway, which was concomitant with an enhanced nitration of the EGF receptor. Preventing nitrogen reactive species formation with MnTBAP, a scavenger of peroxynitrite $\left(\mathrm{ONOO}^{-}\right)$, or using the $\mathrm{ONOO}^{-}$degradation catalyst FeTMPyP, cell proliferation and ERK signaling were restored to basal levels in iNOS ${ }^{+/+}$mixed cultures. Moreover, exposure to the NO donor NOC-18 $(100 \mu \mathrm{M})$, for $48 \mathrm{~h}$, inhibited SVZ-derived NSC proliferation. Regarding the antiproliferative effect of NO, we found that NOC-18 caused the impairment of signaling through the ERK/MAPK pathway, which may be related to increased nitration of the EGF receptor in NSC. Using MnTBAP nitration was prevented, maintaining ERK signaling, rescuing NSC proliferation. We show that NO from inflammatory origin leads to a decreased function of the EGF receptor, which compromised proliferation of NSC. We also demonstrated that NO-mediated nitration of the EGF receptor caused a decrease in its phosphorylation, thus preventing regular proliferation signaling through the ERK/MAPK pathway.

Keywords: inflammation, microglia, nitric oxide, neural stem cells, cell proliferation

\section{INTRODUCTION}

Brain inflammation was shown to be detrimental to neurogenesis (Ekdahl etal., 2003; Monje et al., 2003). However, the inflammatory factors underlying the negative effects of

\footnotetext{
Abbreviations: bFGF, basic fibroblast growth factor; BSA, bovine serum albumin; BrdU, 5-bromo-2'-deoxyuridine; NOC-18, DETA-NONOate; DIV, days in vitro; EdU, 5-ethynyl-2'-deoxyuridine; EGF, epidermal growth factor; EGFR, epidermal growth factor receptor; ERK, extracellular signal-regulated kinase; FeTMPyP, 5,10,15,20-tetrakis(N-methyl-4'-pyridyl)porphinate iron (III) chloride; HBSS, Hank's balanced salt solution; iNOS, inducible nitric oxide synthase; IFN- $\gamma$, interferon-gamma; LPS, lipopolysaccharide; MAPK, mitogenactivated protein kinases; M-CSF, macrophage colony stimulating factor; MnTBAP, Mn(III)tetrakis(4-benzoic acid)porphyrin chloride; NOC-18, (Z)-1-[N(2-aminoethyl)-N-(2-ammonioethyl)amino] diazen-1-ium-1,2-diolate; NO, nitric oxide; 3-NT, 3-nitrotyrosine; NSCs, neural stem cells; $\mathrm{ONOO}^{-}$, peroxynitrite; $\mathrm{PBS}$, phosphate-buffered saline; SVZ, subventricular zone.
}

inflammation on the formation of new brain cells are not fully identified. NSCs and precursors proliferate throughout life in two regions of the adult central nervous system, namely in the SVZ of the lateral ventricles and the subgranular zone (SGZ) of the dentate gyrus of the hippocampus, as reviewed by Ming and Song (2011). Newborn cells can differentiate into various cell types, including neurons and glia (Eriksson et al., 1998; Gage, 2000; Alvarez-Buylla et al., 2002). The proliferation of NSC in the SVZ or SGZ, an initial step in the neurogenic process, increases following several insults to the brain, such as ischemic stroke (Arvidsson et al., 2002) or seizures (Parent et al., 1997), which might be part of the mechanisms supporting self-repair (Lowenstein and Parent, 1999; Curtis et al., 2007). Thus, the identification of potential therapeutic targets for the modulation of endogenous or exogenously induced neurogenesis is of great interest (Taupin, 2005; 
Madhusoodanan and Murad, 2007). Microglial cells are highly dynamic sensors that continually scan the surrounding tissue (Davalos et al., 2005; Nimmerjahn et al., 2005). Upon an injury, or change in the environment, microglia promptly respond with morphological and biochemical changes, producing and releasing a plethora of signaling molecules such as NO (Kettenmann et al., 2011).

Nitric oxide is a highly reactive diffusible signaling molecule, with pleiotropic effects in biological systems, having a half-life of few seconds. Upon neurotoxic, traumatic, and inflammatory damage in the mammalian brain, NO is formed in high amounts, following the expression of the iNOS (Chao et al., 1992; Galea et al., 1992; Nathan and Xie, 1994; Murphy, 2000; Calabrese et al., 2009). The increasing list of functions for NO from inflammatory origin includes bactericidal action, control of cerebral blood flow, regulation of endocytosis and vesicle recycling, and modulation of neurotransmission (Lane and Gross, 1999; Ignarro, 2000; Calabrese et al., 2007). One of the main mechanisms by which $\mathrm{NO}$ exerts its cellular functions is at the level of post-translational protein modification (Guix et al., 2005). Protein nitration results from the reaction of $\mathrm{ONOO}^{-}$, originated by reaction of $\mathrm{NO}$ with superoxide, with amino acidic residues such as tryptophan and tyrosine. Moreover, $S$-nitrosylation occurs when NO reacts with thiol groups of several amino acidic residues, particularly with cysteine. Both nitration and S-nitrosylation typically lead to alterations in protein function, with different outcomes in the cellular metabolism (Hanafy et al., 2001). In fact, reactive nitrogen and oxygen species are important factors in the inflammatory responses mediated by microglial cells (Rock et al., 2004). On the other hand, inflammation has different effects on neurogenesis and, particularly when inflammation occurs following tissue damage, it inhibits the neurogenic process (Ekdahl et al., 2003, 2009; Kempermann and Neumann, 2003; Monje et al., 2003).

Neural progenitor cells in the SVZ are anatomically in close proximity to NO-producing cells (Matarredona et al., 2005). Several studies have suggested that NO inhibits proliferation of NSCs under physiological conditions (Packer et al., 2003; Moreno-Lopez et al., 2004; Matarredona et al., 2005). In isolated NSC from the SVZ, supraphysiological concentrations of NO also inhibit NSC proliferation and promote differentiation of precursors into astrocytes (Covacu et al., 2006; Torroglosa et al., 2007; Bergsland et al., 2014). Torroglosa et al. (2007) have suggested that NO modulates the tyrosine kinase activity of EGF receptor (EGFR), although the precise underlying molecular mechanisms remain unclear. To date, the signaling pathways involved in the proliferative effect of NO following brain injury and the molecular mechanisms of its antiproliferative effect were not identified.

In the present study, we investigated how NO produced by microglia in inflammatory conditions can affect proliferation of NSCs, and assessed the mechanisms underlying the effects of NO on proliferation. To better understand whether and how NO mediates the detrimental effects of inflammation on NSC proliferation, we used a mixed culture system of SVZ-derived stem cells cultured with microglia isolated from wild-type mice (iNOS ${ }^{++}$) or knockout mice (iNOS ${ }^{-/-}$). We show, for the first time, that inflammatory NO produced by microglia has an antiproliferative effect through the decreased activation of the ERK/MAPK signaling pathway, an event for which the nitration of the EGFR plays an essential role, impairing NSC proliferation.

\section{MATERIALS AND METHODS MATERIALS}

Dulbecco's Modified Eagle's Medium:F-12 nutrient mixture (D-MEM/F-12, with GlutaMAX $\left.{ }^{\mathrm{TM}}-\mathrm{I}\right)$, B27 supplement, trypsinEDTA solution $(0.05 \%$ trypsin, $1 \mathrm{mM}$ EDTA in HBSS), gentamicin, antibiotics (10,000 units/ml of penicillin, $10 \mathrm{mg} / \mathrm{ml}$ streptomycin), and trypsin (1:250) were purchased from Life Technologies (Carlsbad, CA, USA). Deoxyribonuclease 1 (DNase-1), BrdU, phenylmethylsufonyl fluoride, dithiothreitol, orthovanadate, chymostatin, leupeptin, antiparin, pepstatin A, trypan blue, LPS, and alkaline phosphatase-linked anti-rabbit secondary antibody were purchased from Sigma Chemical (St Louis, MO, USA). BCATM Protein Assay kit was obtained from Pierce (Rockford, IL, USA). EGF, bFGF, Click-iT ${ }^{\circledR}$ EdU Alexa Fluor ${ }^{\circledR} 647$ HCS Assay, Hoechst 33342, anti-mouse IgG conjugated with Alexa Fluor 594 or 488, and anti-rabbit IgG conjugated with Alexa Fluor 633, 594, or 488 secondary antibodies were purchased from Life Technologies (Carlsbad, CA, USA). Cellulose acetate $(0.45 \mu \mathrm{m})$ was obtained from Corning Inc. (Lowell, MA, USA). M-CSF and IFN- $\gamma$ were purchased from Peprotech (London, UK) and NOC-18 from Alexis Biochemicals (San Diego, CA, USA). BSA and MnTBAP were obtained from Calbiochem (San Diego, CA, USA). The antibody against 3-NT conjugated with agarose beads and FeTMPyP were purchased from Cayman Chemical (Tallinn, Estonia). Rabbit anti-GFAP and DAKO fluorescent mounting medium were obtained from DakoCytomation (Glostrup, Denmark). Rat anti-mouse BrdU was obtained from Oxford Biotechnology and rat anti-mouse CD11b from Serotec (Oxford, UK). Mouse anti-nestin, rabbit anti-iNOS and mouse anti-GAPDH were purchased from BD Transduction (San Jose, CA, USA). Mouse anti-3-nitrotyrosine was purchased from Upstate Biotechnology (Charlottesville, VA, USA), while rabbit anti-EGFR, rabbit anti-phospho-Tyr1173EGFR, rabbit anti-phospho-ERK1/2 and mouse anti-ERK1/2 were purchased from Cell Signaling (Danvers, MA, USA). Rabbit antinestin was obtained from Santa Cruz Biotechnology (Santa Cruz, CA, USA) and mouse anti-Sox-2 from R\&D Systems (Minneapolis, MN, USA). Griess Reagent System was obtained from Promega (Madison, WI, USA). Polyvinylidene difluoride (PVDF) membranes, enhanced chemifluorescence (ECF) reagent and alkaline phosphatase-linked anti-rabbit and anti-mouse secondary antibodies were obtained from Amersham Pharmacia Biotech (Buckinghamshire, UK). Other reagents used in immunoblotting experiments were purchased from BioRad (Hercules, CA, USA).

\section{ANIMALS}

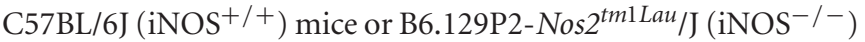
were obtained from Charles River (Barcelona, Spain) or The Jackson Laboratory (Bar Harbor, ME, USA), respectively, and kept with food and water ad libitum in a $12 \mathrm{~h}$ dark:light cycle. All experiments were performed in accordance with NIH and European guidelines (86/609/EEC) for the care and use of laboratory animals. In 
addition, all the people working with animals have received appropriate education (FELASA course) as required by the Portuguese authorities. Furthermore, the animals were housed in our licensed animal facility (International Animal Welfare Assurance number 520.000.000.2006). This study is part of a grant approved and financed by the Foundation for Science and Technology, (FCT, Portugal), that approved the animal experimentation described (reference PTDC/SAU-NEU/102612/2008).

\section{PRIMARY MICROGLIAL CELL CULTURES}

Primary glial cultures were prepared from the brains of 0 to 3-day-

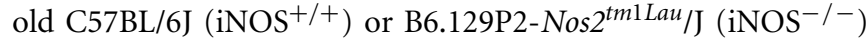
mice according to the method of Giulian and Baker (1986). Briefly, the brains were removed from the skull, following decapitation, and placed in dissection medium composed of $\mathrm{Ca}^{2+}$ and $\mathrm{Mg}^{2+}$-free HBSS $(137 \mathrm{mM} \mathrm{NaCl}, 5.36 \mathrm{mM} \mathrm{KCl}, 0.44 \mathrm{mM}$ $\mathrm{KH}_{2} \mathrm{PO}_{4}, 0.34 \mathrm{mM} \mathrm{Na} \mathrm{PO}_{4} \cdot 2 \mathrm{H}_{2} \mathrm{O}, 4.16 \mathrm{mM} \mathrm{NaHCO} 3,5 \mathrm{mM}$ glucose, $1 \mathrm{mM}$ sodium pyruvate, $10 \mathrm{mM}$ HEPES, $\mathrm{pH}$ 7.4), supplemented with $0.25 \%$ gentamicin. The enveloping meninges and the cerebellum were discarded and the cortex tissue was mechanically dissociated and digested with trypsin $(0.1 \%)$ and DNase 1 $(0.001 \%)$ in $\mathrm{Ca}^{2+}$ - and $\mathrm{Mg}^{2+}$ - free HBSS for $20 \mathrm{~min}$, at $37^{\circ} \mathrm{C}$. Cells were seeded in $75 \mathrm{~cm}^{2}$ flasks coated with poly-L-lysine, at a density of $0.2 \times 10^{6}$ cells $/ \mathrm{cm}^{2}$ and cultured in D-MEM/F-12 with GlutaMAX ${ }^{\mathrm{TM}}$-I supplemented with $10 \% \mathrm{FBS}, 0.25 \%$ gentamicin and $0.25 \mathrm{ng} / \mathrm{ml} \mathrm{M-CSF}$, at $37^{\circ} \mathrm{C}$ and $95 \%$ air- $5 \% \mathrm{CO}_{2}$ in a humidified incubator. Culture medium was changed every 34 days and confluency was achieved after 10-14 DIV. Microglia were detached from the mixed glial cultures 3-10 days after reaching confluency, by shaking at $200 \mathrm{rpm}$ for $2 \mathrm{~h}$, and collected from the supernatant by centrifuging at $1500 \mathrm{rpm}$, for $5 \mathrm{~min}$. Cells were then seeded for 3 days at a density of $0.035 \times 10^{6}$ cells $/ \mathrm{cm}^{2}$ onto 16-mm diameter glass coverslips, for immunocytochemistry assays, or on 12-well plates, for preparation of lysates, both coated with poly-L-lysine, in serum-free medium, without M-CSF. Next, cultures were treated with an acute inflammatory stimulus (except the controls): $100 \mathrm{ng} / \mathrm{ml}$ LPS plus $0.5 \mathrm{ng} / \mathrm{ml}$ IFN- $\gamma$, for $24 \mathrm{~h}$ (Saura et al., 2003).

\section{SUBVENTRICULAR ZONE CELL CULTURES}

Neural stem cell cultures were obtained from the SVZ of postnatal day 0-3 wild-type or transgenic C57BL/6J mice expressing enhanced green fluorescent protein (GFP) under the control of the actin promoter, as previously described by Carreira et al. (2010). The SVZ-derived NSCs were allowed to develop as primary neurospheres in a $95 \%$ air- $5 \% \mathrm{CO}_{2}$ humidified atmosphere at $37^{\circ} \mathrm{C}$, during 7 days. Next, neurospheres were collected, dissociated and plated for 5 days on 16-mm diameter glass coverslips, for immunocytochemistry assays, or on 12-well plates, coated with poly-L-lysine, in the same medium as above, without growth factors, for preparation of lysates.

\section{MIXED CELL CULTURES}

Green fluorescent protein-positive SVZ neurospheres were collected, dissociated and plated together with iNOS $+/+$ or iNOS $-1-$ microglial cell cultures (from now on denominated as iNOS $+/+$ or iNOS $^{-/-}$mixed cultures, respectively) on $16-\mathrm{mm}$ diameter glass coverslips, for immunocytochemistry assays, or on 12-well plates, for preparation of lysates, both coated with poly-L-lysine, and kept in fresh D-MEM/F-12 with GlutaMAX ${ }^{\mathrm{TM}}$-I medium, supplemented with $1 \% \mathrm{~B} 27,0.25 \%$ gentamicin, $10 \mathrm{ng} / \mathrm{ml} \mathrm{EGF}$ and $10 \mathrm{ng} / \mathrm{ml} \mathrm{bFGF}$, at $37^{\circ} \mathrm{C}$ and $95 \%$ air- $5 \% \mathrm{CO}_{2}$ in a humidified incubator, for 3 days. GFP-positive SVZ neurospheres were also dissociated and seeded alone, for 3 days, on 16-mm diameter coverslips or on 12-well plates, coated with poly-L-lysine, and cultured in the same medium as above, for control experiments. Cultures were treated with $100 \mathrm{ng} / \mathrm{ml}$ LPS plus $0.5 \mathrm{ng} / \mathrm{ml} \mathrm{IFN-} \gamma$, for $24 \mathrm{~h}$. Control cultures were left untreated. The cell-permeable superoxide dismutase mimetic and $\mathrm{ONOO}^{-}$scavenger MnTBAP (100 $\mu \mathrm{M}$; Szabo et al., 1996) or the $\mathrm{ONOO}^{-}$decomposition catalyst FeTMPyP (50 $\mu$ M; Misko et al., 1998), when used, were added 30 min before LPS plus IFN- $\gamma$ and kept throughout the incubation period.

\section{EXPERIMENTAL TREATMENTS IN SVZ-DERIVED NEURAL STEM CELL CULTURES}

Subventricular zone-derived NSC were exposed to the NO donor NOC-18 $(100 \mu \mathrm{M})$ for $48 \mathrm{~h}$. MnTBAP $(100 \mu \mathrm{M})$ and FeTMPyP $(50 \mu \mathrm{M})$, were added $30 \mathrm{~min}$ before NOC-18 and kept throughout the incubation period.

\section{DETECTION OF BrdU INCORPORATION IN SVZ-DERIVED NEURAL STEM CELL CULTURES}

To analyze proliferation of SVZ-derived NSCs, $10 \mu \mathrm{M}$ BrdU was added to the cultures $16 \mathrm{~h}$ prior to fixation (Alvaro et al., 2008; Carreira et al., 2010). Nuclei that incorporated BrdU in this timewindow were detected by immunofluorescence, as detailed next. Following $20 \mathrm{~min}$ fixation with $4 \%$ paraformaldehyde/4\% sucrose in PBS $(0.1 \mathrm{M})$, the cells were permeabilized with $1 \%$ Triton X-100 for $5 \mathrm{~min}$, and DNA was denaturated by treatment with $1 \mathrm{M} \mathrm{HCl}$ for $30 \mathrm{~min}$, at $37^{\circ} \mathrm{C}$. Non-specific binding was blocked with $3 \%$ BSA in $0.2 \%$ Tween-20 in PBS (PBS-T) for $1 \mathrm{~h}$, and then BrdUpositive cells were labeled with a rat anti-BrdU antibody (1:50) for $90 \mathrm{~min}$, at room temperature. The cells were then incubated with a secondary antibody goat anti-rat IgG conjugated with Alexa Fluor 594 (1:200), for $1 \mathrm{~h}$, at room temperature. Nuclei were stained with Hoechst $33342(1 \mu \mathrm{g} / \mathrm{ml})$ for $5 \mathrm{~min}$. Coverslips were mounted on glass slides using DAKO fluorescence mounting medium. The images were acquired in a laser-scanning microscope LSM 510 META (Zeiss, Jena, Germany) or in a fluorescence microscope (Axioskop 2 Plus, Zeiss, Jena, Germany). The number of BrdUpositive nuclei was counted in 8-10 randomly selected fields for each coverslip (in a total of 900-1,200 cells per coverslip), and the data were expressed as percentage of the total number of live cells. A minimum of three independent experiments, from NSC cultures prepared from different animals, was analyzed for each condition.

\section{DETECTION OF EdU INCORPORATION}

Neural stem cell proliferation was also assessed by incorporation of the thymidine analog EdU, which is incorporated into DNA of dividing cells during S phase (Buck et al., 2008; Cappella et al., 2008; Chehrehasa et al., 2009). EdU (10 $\mu \mathrm{M})$ was added to the cultures $4 \mathrm{~h}$ prior to fixation. Nuclei that incorporated 
EdU in this time-window were detected by immunofluorescence, as follows. Following $20 \mathrm{~min}$ fixation with $4 \%$ paraformaldehyde/4\% sucrose in PBS $(0.1 \mathrm{M})$, the cells were washed with $3 \%$ BSA/PBS and then permeabilized with $0.5 \%$ Triton X-100/PBS for $15 \mathrm{~min}$, at room temperature. The cells were then incubated with the Click-iT reaction cocktail [ $1 \mathrm{x}$ at $87.5 \%(\mathrm{v} / \mathrm{v})$ Click-iT Reaction Buffer, 2\% (v/v) $\mathrm{CuSO}_{4}, 0.05 \%(\mathrm{v} / \mathrm{v})$ fluorescent azide (Alexa Fluor 647), and $1 \mathrm{x}$ at $10 \%(\mathrm{v} / \mathrm{v})$ Reaction Buffer Additive], protected from light. Cells were then washed twice in $3 \%$ BSA/PBS and an immunocytochemistry was performed as detailed next.

The number of EdU-positive nuclei was counted in 8-10 randomly selected fields for each coverslip (in a total of $\sim 900-1,200$ cells per coverslip), and the data were expressed as percentage of the total number of live cells. A minimum of three independent experiments was analyzed for each condition.

\section{IMMUNOCYTOCHEMISTRY}

Following fixation and permeabilization, non-specific binding was blocked with 3\% BSA. Cells were incubated with the primary antibodies for $90 \mathrm{~min}$, at room temperature. After rinsing with PBS, the cells were incubated with the appropriate secondary antibodies

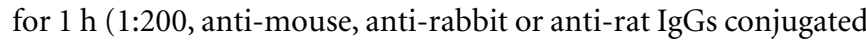
with Alexa Fluor 488, 594, or 633), at room temperature. All antibodies were prepared in blocking solution. Nuclei were labeled with Hoechst $33342(1 \mu \mathrm{g} / \mathrm{ml})$ for $5 \mathrm{~min}$, after incubation with the secondary antibodies. Coverslips were mounted on glass slides, the cells were visualized using a fluorescence microscope (Axioskop 2 Plus, Zeiss, Jena, Germany) and the images were acquired with the Axiovision software (release 4.7) or in a laser scanning fluorescence microscope LSM 510 META (Zeiss, Jena, Germany). The primary antibodies and the concentrations used were: mouse antiSox-2, 1:100; rabbit anti-nestin, 1:100; rabbit anti-GFAP, 1:400; mouse anti-nestin, 1:500; rat anti-mouse-CD11b, 1:200; rabbit anti-iNOS, 1:200.

\section{EVALUATION OF NITRIC OXIDE PRODUCTION}

Nitric oxide production was indirectly assessed by measuring the concentration of nitrites in the culture medium (Green et al., 1982), in primary microglia cultures, SVZ-derived NSC cultures or mixed cell cultures. A commercial kit from Promega was used, and the standard protocol provided by the supplier was followed. The concentration of nitrite for each sample was calculated from a standard curve using a sodium nitrite solution and data were expressed in $\mu \mathrm{M}$.

\section{WESTERN BLOT ANALYSIS}

Cells were lysed in $50 \mathrm{mM}$ Tris- $\mathrm{HCl}, 10 \mathrm{mM}$ EGTA, 1\% Triton $\mathrm{X}-100$ and $2 \mathrm{mM} \mathrm{MgCl}_{2}$, supplemented with $100 \mu \mathrm{M}$ phenylmethylsufonyl fluoride, $1 \mathrm{mM}$ dithiothreitol, $1 \mu \mathrm{g} / \mathrm{ml}$ chymostatin, $1 \mu \mathrm{g} / \mathrm{ml}$ leupeptin, $1 \mu \mathrm{g} / \mathrm{ml}$ antiparin, $5 \mu \mathrm{g} / \mathrm{ml}$ pepstatin A, $1 \mathrm{mM}$ sodium orthovanadate, $50 \mathrm{mM} \mathrm{NaF}, \mathrm{pH} 7.4$, at $4^{\circ} \mathrm{C}$. Protein concentration was determined by the bicinchoninic acid (BCA) method, and the samples were used for Western blot analysis, after adding $6 \mathrm{x}$ concentrated sample buffer [0.5 M Tris, 30\% glycerol, $10 \%$ sodium dodecyl sulfate (SDS), $0.6 \mathrm{M}$ dithiothreitol, $0.012 \%$ bromophenol blue] and heating, for $5 \mathrm{~min}$, at $95^{\circ} \mathrm{C}$.
Equal amounts of protein were separated by electrophoresis on SDS-polyacrylamide gels, and transferred electrophoretically to PVDF membranes. These were then blocked for $1 \mathrm{~h}$ at room temperature, in Tris-buffered saline ( $137 \mathrm{mM} \mathrm{NaCl}, 20 \mathrm{mM}$ Tris$\mathrm{HCl}, \mathrm{pH} 7.6$ ) containing $0.1 \%$ Tween-20 (TBS-T) and 3\% BSA. Incubations with primary antibodies (anti-iNOS or anti-GAPDH, 1:500; rabbit anti-phospho-Tyr1173-EGFR, rabbit anti-EGFR, rabbit anti-phospho-ERK1/2 and mouse anti-ERK1/2, 1:1,000) in TBS-T with $1 \%$ BSA were performed overnight, at $4^{\circ} \mathrm{C}$. Next, the membranes were incubated for $1 \mathrm{~h}$ at room temperature with alkaline phosphatase-linked secondary antibodies (anti-rabbit or anti-mouse IgG, 1:20,000) in TBS-T with 1\% BSA. After extensive washing in TBS-T with $0.5 \%$ BSA, immunoreactive bands were visualized in the VersaDoc 3000 imaging system (BioRad, Hercules, CA, USA), following incubation of the membrane with ECF reagent for $5 \mathrm{~min}$.

\section{IMMUNOPRECIPITATION}

Following the various experimental treatments, as detailed in figure legends, the cultures were lysed in $20 \mathrm{mM}$ Tris- $\mathrm{HCl}, 100 \mathrm{mM}$ $\mathrm{NaCl}, 2 \mathrm{mM}$ EDTA, $2 \mathrm{mM}$ EGTA, supplemented with $100 \mu \mathrm{M}$ PMSF, $1 \mathrm{mM}$ dithiothreitol, $1 \mu \mathrm{g} / \mathrm{ml}$ chymostatin, $1 \mu \mathrm{g} / \mathrm{ml}$ leupeptin, $1 \mu \mathrm{g} / \mathrm{ml}$ antiparin, $5 \mu \mathrm{g} / \mathrm{ml}$ pepstatin $\mathrm{A}, 1 \mathrm{mM}$ sodium orthovanadate, $50 \mathrm{mM} \mathrm{NaF}, \mathrm{pH} 7.0$, at $4^{\circ} \mathrm{C}$. Protein concentration was determined by the BCA method, and the samples were used for immunoprecipitation of nitrated proteins, using an antibody against 3-NT conjugated with agarose beads. Briefly, equal amounts of sample ( $250 \mu \mathrm{g}$ of protein) were incubated with the antibody overnight at $4^{\circ} \mathrm{C}$, and then with the beads for $2 \mathrm{~h}$ at room temperature. Following rinsing, the supernatant was discarded and the beads were suspended in $2 \mathrm{x}$ concentrated sample buffer, boiled for $5 \mathrm{~min}$, and centrifuged using Spin-X centrifuge tube filters $(0.45 \mu \mathrm{m}$ cellulose acetate), to separate the beads from the immunoprecipitates. Equal volumes of immunoprecipitate were loaded onto SDS-PAGE gels, and Western blotted as described above against the EGF receptor.

\section{STATISTICAL ANALYSIS}

Data are expressed as mean \pm SEM. Statistical significance was determined by using two-tailed $t$-tests, one-factor or two-factor analysis of variance (ANOVA) as appropriate, followed by post hoc Bonferroni's or Dunnet's tests, as indicated in the figure legends and in the text. Differences were considered significant when $p<0.05$.

\section{RESULTS \\ INFLAMMATORY STIMULATION INCREASES INOS EXPRESSION AND NO FORMATION}

Neural stem cells were isolated from the SVZ and cultured as floating aggregates, also referred as neurospheres. Neurospheres were then dissociated and plated on poly-L-lysine-coated coverslips for 3-5 days, and characterized at this stage. Staining against the transcription factor Sox-2, and against nestin, a neural precursor cell marker, was performed. The percentage of double-labeled cells was approximately $70 \%$, which suggests that the majority of cells remained undifferentiated after plating as shown previously by our group (Carreira et al., 2010). 
Microglial cells were seeded on poly-L-lysine-coated coverslips for 3 days and challenged with an inflammatory stimulus, LPS $(100 \mathrm{ng} / \mathrm{ml})$ plus IFN- $\gamma(0.5 \mathrm{ng} / \mathrm{ml})$, for $24 \mathrm{~h}$. Cultures were then characterized by evaluating microglial cells morphology, iNOS expression and NO production. In iNOS ${ }^{+/+}$microglial cell cultures, exposure to LPS plus IFN- $\gamma$ increased iNOS immunoreactivity, but not in iNOS ${ }^{-/-}$microglial cell cultures (Figure 1A), as expected. Concomitantly, following treatment with LPS plus IFN- $\gamma$, both iNOS ${ }^{+/+}$and iNOS $^{-/-}$microglial cells exhibited an activated morphology with ovaloid cytoplasm, marked cellular hypertrophy and retraction of processes. In order to estimate the amount of NO produced by activated microglia in culture, we assessed NO production by measuring nitrite levels in the culture media following challenging with LPS plus IFN- $\gamma$. Nitrite levels were higher in treated iNOS ${ }^{+/+}$microglial cell cultures $(1.95 \pm 0.3 \mu \mathrm{M}, p<0.001)$, than in untreated cultures $(0.32 \pm 0.1 \mu \mathrm{M})$, corresponding to a 6 -fold increase in NO production above control levels. In iNOS ${ }^{-/-}$microglial cell cultures, treatment with LPS plus IFN- $\gamma$ did not significantly change NO levels, as compared to untreated cultures (Figure 1B).

To investigate how inflammation, particularly NO formed due to microglial activation, could affect the proliferation of SVZderived NSCs, mixed cultures were prepared as described in Section "Materials and Methods." We evaluated the expression of iNOS in iNOS $+/+$ mixed cultures, following treatment with LPS plus IFN- $\gamma$ by immunocytochemistry (Figure 2A) and Western blot analysis (Figure 2B). In iNOS ${ }^{-/-}$mixed cultures, iNOS was not detected, as assessed by Western blotting, even after the inflammatory stimulus (Figure 2B). Furthermore, when measuring nitrite levels in the culture media, an increase in NO production was observed in iNOS $^{+/+}$mixed cultures $(1.96 \pm 0.2 \mu \mathrm{M}$, $p<0.001)$ following treatment with LPS plus IFN- $\gamma$, as compared to control cultures $(0.39 \pm 0.1 \mu \mathrm{M})$. On the contrary, treatment with LPS plus IFN- $\gamma$ for $24 \mathrm{~h}$ did not significantly change NO levels in iNOS $^{-/-}$mixed cultures, as compared to untreated cultures (Figure 2C).

To determine whether SVZ-derived NSCs contributed to the increase in iNOS levels observed in mixed cell cultures, we also evaluated the presence of iNOS in SVZ-derived NSC alone, and observed a complete absence of immunoreactivity against iNOS following treatment with LPS plus IFN- $\gamma$ in these cultures (Figure 2D). Moreover, treatment with LPS plus IFN- $\gamma$ for $24 \mathrm{~h}$ did not significantly change NO levels in SVZ-derived NSC cultures, as compared to untreated cultures, as assessed by evaluating nitrite levels in cultures (Figure 2E).

\section{NO FROM INFLAMMATORY ORIGIN EXERTS AN ANTIPROLIFERATIVE EFFECT ON SVZ-DERIVED NEURAL STEM CELLS}

To determine how NO released from microglial cells affected the proliferation of SVZ-derived NSCs, we evaluated the incorporation of EdU in iNOS $+/+$ or iNOS ${ }^{-/-}$mixed cultures, following treatment with LPS plus IFN- $\gamma$. In iNOS $+/+$ mixed cultures, we observed that EdU incorporation significantly decreased to $7.0 \pm 1.09 \%(p<0.001), 24 \mathrm{~h}$ following exposure to LPS plus IFN$\gamma$, as compared to control cultures $(17.3 \pm 0.88 \%)$, but the same stimulus had no effect in EdU incorporation either in iNOS ${ }^{-/-}$ mixed cultures or in SVZ-derived NSC cultures alone (Figure 3A).

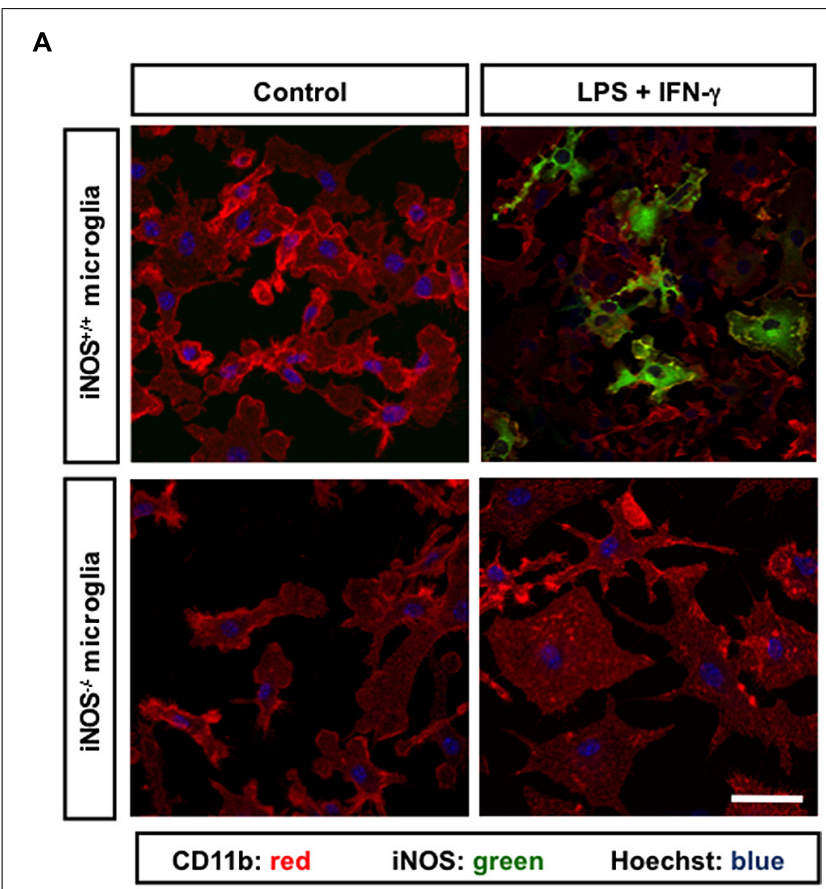

B

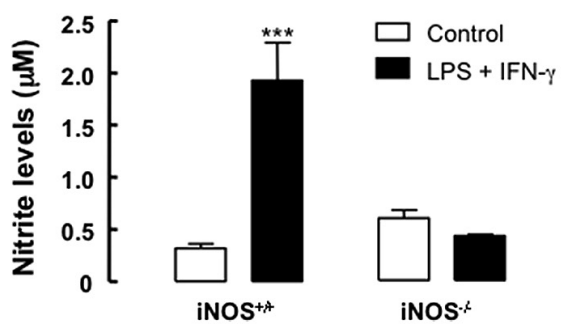

FIGURE 1 | Nitric oxide production and iNOS expression in primary microglial cell cultures under inflammatory conditions. (A) Exposure to LPS plus IFN- $\gamma$ for $24 \mathrm{~h}$ triggered the expression of iNOS in iNOS $+/+$ microglia (CD11b-positive cells), but not in iNOS $-/-$ microglia. Nuclei were labeled with Hoechst 33342. Scale bar: $20 \mu \mathrm{m}$. (B) Production of NO, which was indirectly measured by quantification of nitrite levels in the culture media, following treatment with LPS plus IFN- $\gamma$ for $24 \mathrm{~h}$, in primary iNOS $^{+/+}$or iNOS $-/-$microglial cell cultures. Two-way ANOVA;

${ }^{* *} p<0.001$, significantly different from control.

Moreover, we observed that SVZ-derived NSCs, but not microglia, incorporated EdU, as illustrated by the presence of immunoreactivity against EdU in the GFP-positive SVZ cells, but not in microglial cells, strongly suggesting that these are the dividing cells in mixed cultures (Figure 3B). We also confirmed that LPS plus IFN- $\gamma$ for $24 \mathrm{~h}$ did not affect cell viability in iNOS ${ }^{+/+}$ and in iNOS ${ }^{-/-}$mixed cultures, or in SVZ-derived NSC cultures (Tables 1 and 2, respectively).

\section{NO FROM INFLAMMATORY ORIGIN DECREASES THE ACTIVATION OF THE ERK/MAPK SIGNALING PATHWAY}

We next investigated the possible mechanism underlying the observed antiproliferative effect of inflammation in mixed 
A

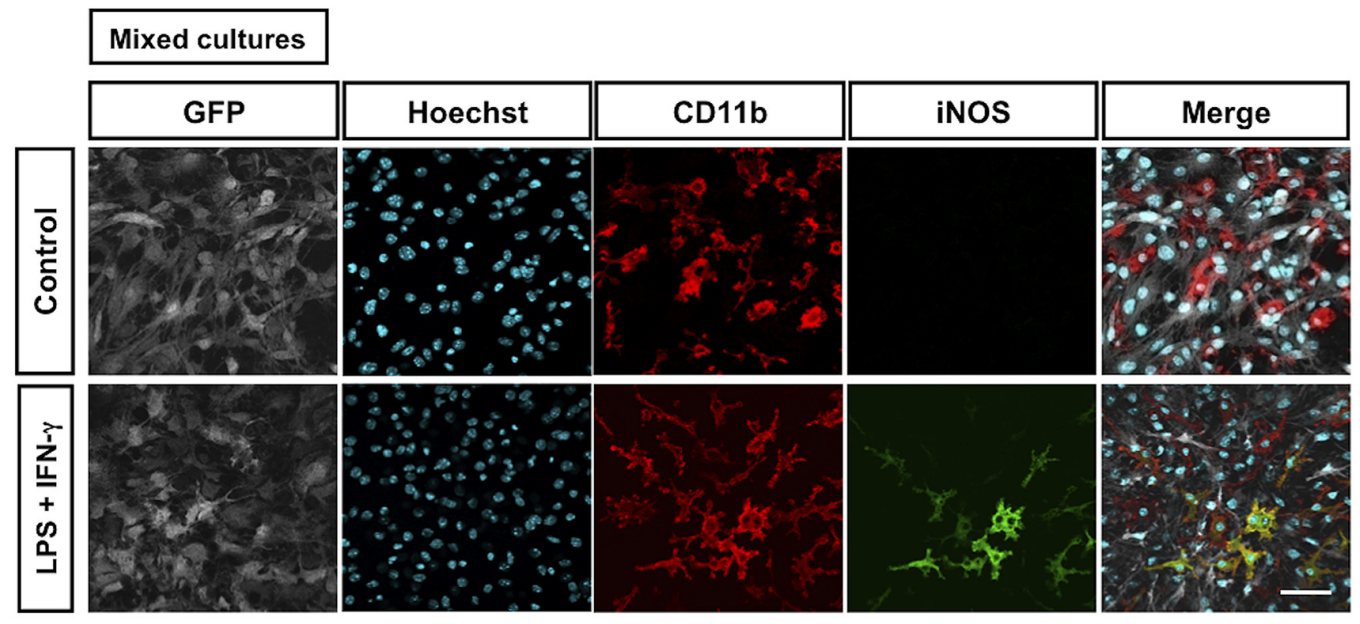

B

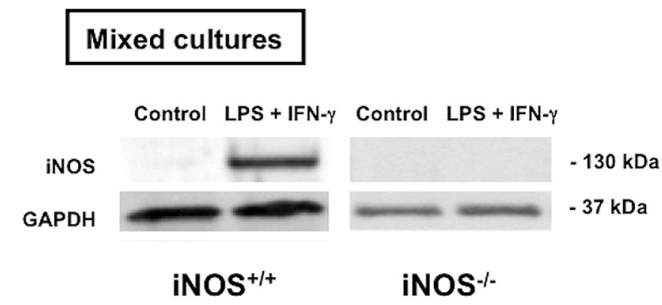

D

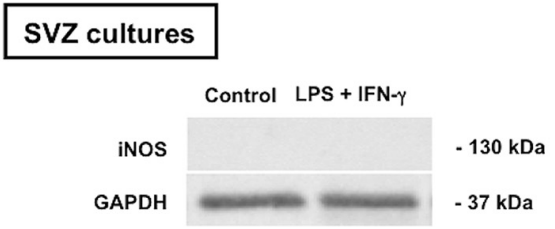

C

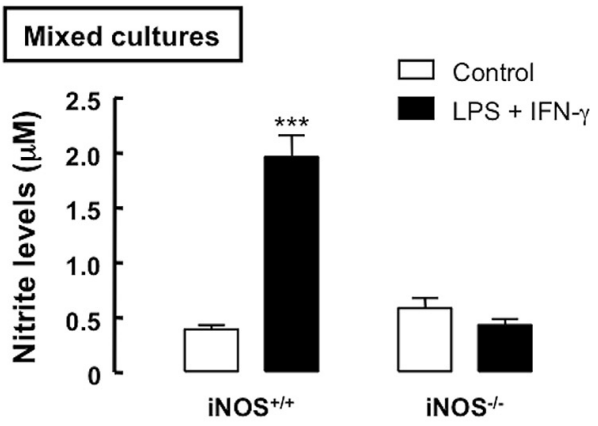

E

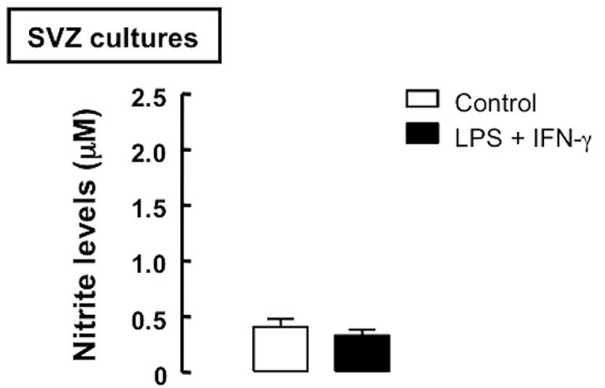

LPS plus IFN- $\gamma$ for $24 \mathrm{~h}$, as assessed by Western blotting. GAPDH was used as a loading control. (C) Production of NO, following $24 \mathrm{~h}$ treatment with LPS plus IFN- $\gamma$, in mixed cultures. Two-way ANOVA; ${ }^{* * *} p<0.001$, significantly different from control. (D) Absence of iNOS immunoreactivity in SVZ cells cultured alone, upon exposure to LPS plus IFN- $\gamma$ for $24 \mathrm{~h}$. GAPDH was used as loading control. (E) NO production after $24 \mathrm{~h}$ of treatment with LPS plus IFN- $\gamma$, in SVZ-derived NSC cultures. Two-tailed $t$-test; $p>0.05$. cultures. The main regulatory pathway for NSC proliferation is the signaling cascade of MAPK, particularly the ERK1/2 pathway. Within this scenario, we evaluated whether inflammation, particularly NO from inflammatory origin, could affect the activation and signaling through the ERK/MAPK pathway. We found that LPS plus IFN- $\gamma$ decreased the phosphorylation of ERK1/2 in iNOS $^{+/+}$mixed cultures (Figure 4, $p<0.001$ ), whereas in iNOS $^{-/-}$mixed cultures no changes were observed in the levels of phospho-ERK1/2 following exposure to LPS plus IFN- $\gamma$ (Figure 4). 
A

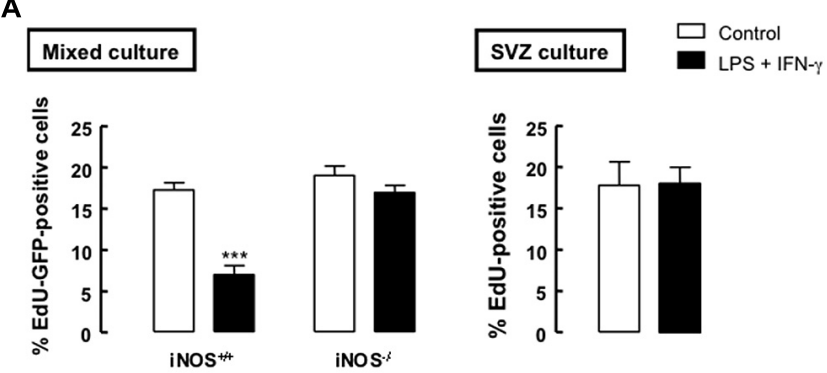

B

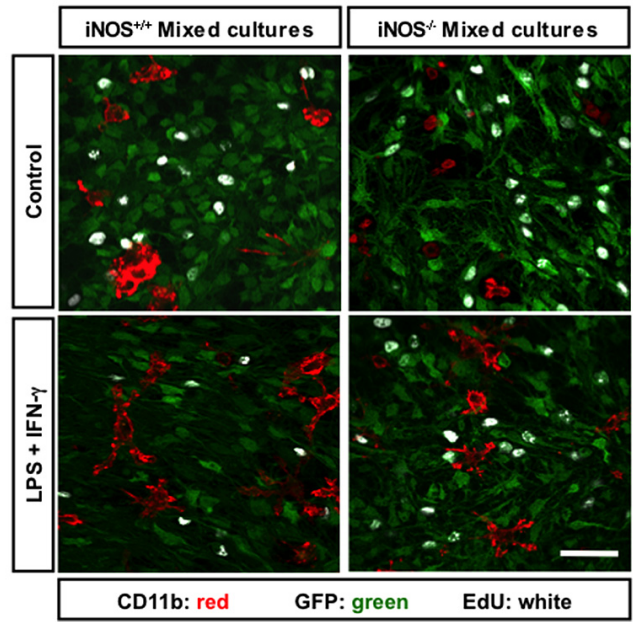

FIGURE 3 | Nitric oxide from microglial origin impairs the proliferation of SVZ cells. (A) Incorporation of EdU in mixed or SVZ-derived NSC cultures following treatment with LPS plus IFN- $\gamma$ for $24 \mathrm{~h}$. Two-way ANOVA (mixed culture); ${ }^{* *} p<0.001$, significantly different from control. Two-tailed $t$-test
(SVZ culture); $p>0.05$. (B) Representative images of the incorporation of EdU (white) in GFP-positive SVZ cells (green) cultured together with iNOS $+/+$ or iNOS $-/-$ microglia (CD11b-positive cells; red), following $24 \mathrm{~h}$ exposure to LPS plus IFN- $\gamma$. Scale bar: $20 \mu \mathrm{m}$.
To better understand whether the antiproliferative effect of inflammation in mixed cultures could be due to the production of highly reactive species, such as $\mathrm{ONOO}^{-}$, we used MnTBAP, a superoxide scavenger, thus preventing the production of $\mathrm{ONOO}^{-}$, and FeTMPyP, which catalyzes the degradation of $\mathrm{ONOO}^{-}$. We observed that the decreased phosphorylation of ERK1/2 in iNOS $+/+$ mixed cultures following treatment with LPS plus IFN- $\gamma$ was prevented either by treatment with MnTBAP or FeTMPyP (Figure 5A, $p<0.001$ or $p<0.05$, respectively). Moreover, when MnTBAP or FeTMPyP were present during the inflammatory stimulus, cell proliferation was rescued to $15.8 \pm 0.4 \%$ or $14.7 \pm 0.8 \%$, respectively, in iNOS $^{+/+}$mixed cultures (Figures 5B,C).

We also investigated the effect of high levels of NO, an event occurring during inflammation, in the proliferation of SVZderived NSC cultures. For that, SVZ-derived NSCs were exposed to a NO donor, NOC-18 (100 $\mu \mathrm{M})$, for $48 \mathrm{~h}$. We observed a decreased phosphorylation of ERK1/2, following exposure to $100 \mu \mathrm{M}$ NOC18 for $48 \mathrm{~h}$, which was prevented by MnTBAP (Figure 6A, $p<0.05)$. When assessing NSC proliferation by evaluating BrdU incorporation following treatment with NOC-18 $(100 \mu \mathrm{M})$ for $48 \mathrm{~h}$, we observed that NOC-18 significantly decreased BrdU incorporation to $4.9 \pm 0.2 \%(p<0.001)$, as compared to $\mathrm{BrdU}$ incorporation in control cultures $(7.7 \pm 0.2 \%)$. Interestingly, MnTBAP rescued cell proliferation $(7.9 \pm 0.66 \%)$, when present during the treatment with NOC-18 for $48 \mathrm{~h}$ (Figure 6B). Furthermore, we also confirmed that NOC-18 for $48 \mathrm{~h}$ did not affect cell viability in SVZ-derived NSC cultures (Table 2).

\section{INFLAMMATION INDUCES NITRATION OF THE EGF RECEPTOR AND DECREASES ITS PHOSPHORYLATION STATUS}

We next evaluated whether the inflammatory stimulus induced the nitration of the EGF receptor in mixed cultures, an event that could be linked to the inhibition of the downstream signaling through the ERK/MAPK pathway in mixed cultures treated with LPS plus IFN- $\gamma$. Nitration of tyrosine residues of the EGFR was evaluated in iNOS $^{+/+}$and iNOS $^{-/-}$mixed cultures. In iNOS $+/+$ mixed cultures, treatment with LPS plus IFN- $\gamma$ for $24 \mathrm{~h}$ increased the nitration of the EGFR in immunoprecipitates of nitrated proteins $(127.4 \pm 5.4 \%, p<0.01)$, as compared to untreated cultures. Moreover, MnTBAP and FeTMPyP were able to prevent the nitration of the EGFR in these cultures, after incubation with LPS plus IFN- $\gamma$, reducing EGFR nitration to $68.2 \pm 7.2 \%(p<0.001)$ or $84.9 \pm 2.4 \%(p<0.001)$ of the control, respectively (Figure 7A, left pannel). On other hand, this effect was not observed in iNOS $^{-/-}$mixed cultures, where treatment with LPS plus IFN- $\gamma$ 
Table 1 | Cell viability evaluation in iNOS ${ }^{+/+}$and iNOS ${ }^{-/-}$mixed cultures following exposure to LPS plus IFN- $\gamma$ for $24 \mathrm{~h}$.

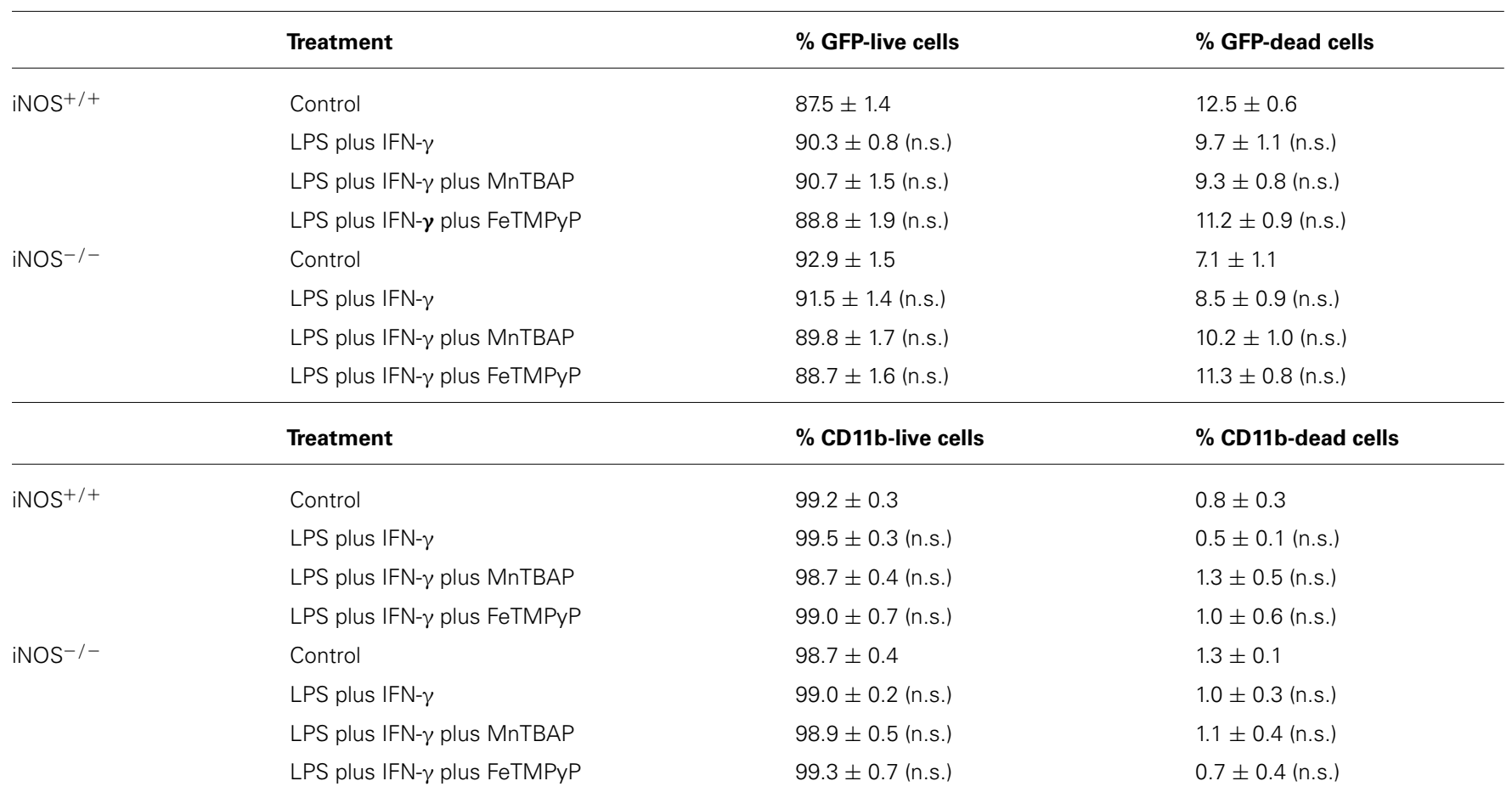

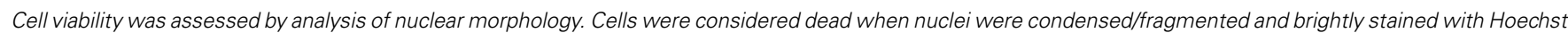

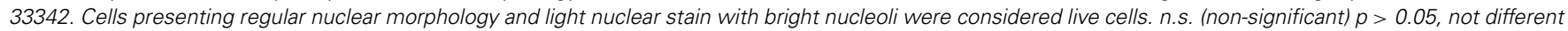
from the control, one-way ANOVA (Dunnett's post-test).

did not cause increased nitration of the EGFR (Figure 7A, right panel).

Next, we analyzed the phosphorylation of the tyrosine residue 1173, which is involved in the activation of the EGFR. LPS plus IFN- $\gamma$ caused a decrease in the phosphorylation status of the EGFR in iNOS $^{+/+}$mixed cultures, an event that was prevented either by MnTBAP or FeTMPyP (Figure 7B, left panel). As expected, in iNOS $^{-/-}$mixed cultures no changes were observed in the phosphorylation status of the EGFR following exposure to LPS plus IFN- $\gamma$ for $24 \mathrm{~h}$ (Figure 7B, right panel).

\section{DISCUSSION}

In this work, we demonstrated that inflammation has an antiproliferative effect on NSC. Furthermore, we show that the inhibitory effect of inflammation on the proliferation of NSC is mediated by $\mathrm{NO}$, due to the decreased signaling through the ERK/MAPK pathway, subsequent to the nitration of the EGF receptor and decrease of its phosphorylation status.

The effect of inflammation on the proliferation of SVZderived NSCs was studied in this work by establishing mixed cultures of $\mathrm{iNOS}^{+/+}$or iNOS $^{-/-}$microglial cells and SVZderived NSCs. These mixed cultures, when challenged with LPS plus IFN- $\gamma$, are a good system to mimic events occurring in vivo during an inflammatory response (Cacci et al., 2008) in the neurogenic niche, particularly NO production, thus allowing us to dissect the involved of NO and underlying mechanism in the antiproliferative effect of neuroinflammation. To study more directly the effect of NO in SVZ-derived NSCs, primary
SVZ-derived cell cultures were exposed to high levels of the NO donor (NOC-18), an experimental condition that mimics pathophysiological conditions, particularly neuroinflammatory conditions, when high concentrations of NO can be found locally in the brain. For this purpose, SVZ-derived NSCs cultures were incubated with $100 \mu \mathrm{M}$ NOC-18 for $48 \mathrm{~h}$, since it is a long-acting NO donor with a half-life of $\sim 22 \mathrm{~h}$ (Keefer et al., 1996). At this concentration $(100 \mu \mathrm{M})$, NOC-18 released NO mimicking what might be found in neuroinflammatory conditions. We did not observe any cytotoxic effect of NO in

Table 2 | Cell viability evaluation in SVZ-derived NSC cultures.

\begin{tabular}{|c|c|c|c|}
\hline & Treatment & $\%$ live cells & $\%$ dead cells \\
\hline \multirow[t]{2}{*}{$24 \mathrm{~h}$} & Control & $92.7 \pm 0.9$ & $7.3 \pm 0.5$ \\
\hline & LPS plus IFN- $\gamma$ & $90.5 \pm 0.5$ (n.s.) & $9.5 \pm 0.9$ (n.s.) \\
\hline \multirow[t]{4}{*}{$48 \mathrm{~h}$} & Control & $80.0 \pm 2.0$ & $20.0 \pm 1.0$ \\
\hline & NOC-18 & $77.5 \pm 2.8$ (n.s.) & $22.5 \pm 1.2$ (n.s.) \\
\hline & NOC-18 plus MnTBAP & $80.2 \pm 1.7$ (n.s.) & $19.8 \pm 0.9$ (n.s.) \\
\hline & MnTBAP & $82.6 \pm 1.3$ (n.s.) & $17.4 \pm 0.8$ (n.s.) \\
\hline
\end{tabular}

Cell viability was assessed by analysis of nuclear morphology. Cells were considered dead when nuclei were condensed/fragmented and brightly stained with Hoechst 33342. Cells presenting regular nuclear morphology and light nuclear stain with bright nucleoli were considered live cells. n.s. (non-significant) $p>0.05$, not different from the control, two-tailed t-test (24 h analysis) or one-way ANOVA (48 $h$ analysis; Dunnett's post-test). 

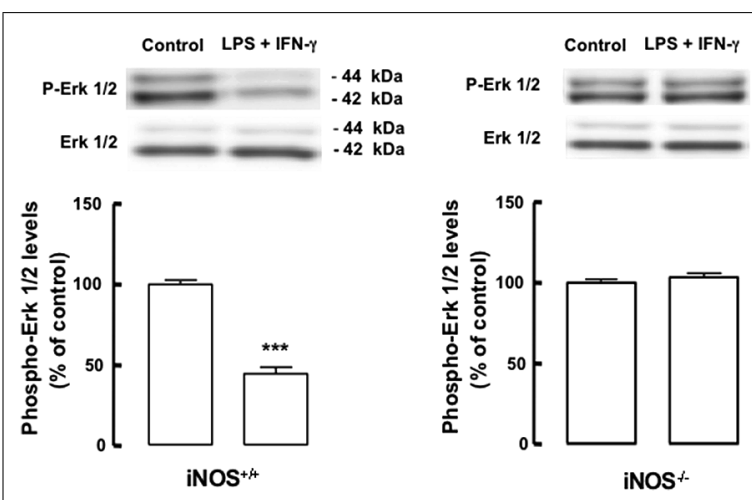

FIGURE 4 | Nitric oxide from microglia origin decreases the activation of the ERK1/2 signaling pathway. Decreased phosphorylation of ERK1/2 in iNOS $+/+$ mixed culture, but not in iNOS $-/-$ mixed culture lysates, following exposure to LPS plus IFN- $\gamma$. One-way ANOVA (Bonferroni's post-test). ${ }^{* *} p<0.001$, significantly different from control.

all the conditions tested in this study (Boje and Arora, 1992; Dawson et al., 1993, 1994; Bal-Price and Brown, 2001). In addition, we assessed the activation of the ERK/MAPK signaling pathway, which is involved in the regulation of SVZ-derived NSC proliferation downstream of EGFR (Reynolds and Weiss, 1996; Doetsch et al., 2002; Carreira et al., 2010, 2012). High levels of NO, achieved following treatment with NOC-18, decreased the phosphorylation of ERK1/2 in SVZ-derived NSC cultures, suggesting an inhibition of the signaling pathway controlling NSC proliferation after exposure to NO. MnTBAP prevented the decrease in the phosphorylation of ERK1/2 and was also able to rescue cell proliferation to control levels, suggesting that the antiproliferative effect of NO is mostly due to the formation of nitrogen reactive species, which compromises signaling through the MAPK pathway.

Furthermore, we show that LPS plus IFN- $\gamma$ decreased the activation of the ERK pathway downstream of the EGFR in iNOS $+/+$ mixed cultures, which was prevented by MnTBAP and FeTMPyP. This event was not observed in iNOS $^{-/-}$mixed cultures, where no differences were found in the phosphorylation status of ERK following treatment with LPS plus IFN- $\gamma$. Here we hypothesized that the antiproliferative effect of inflammation is mediated by NO production, causing a decreased signaling through the ERK/MAPK pathway. This event might be mediated by intermediate formation of nitrogen reactive species, such as $\mathrm{ONOO}^{-}$, since high levels of NO can inhibit mitochondrial respiration and elicit superoxide production (Beltran et al., 2002; Moncada and Bolanos, 2006; Calabrese et al., 2009). Different mechanisms by which microglia impairs neurogenesis in inflammatory conditions have been reported, which involves the release of proinflammatory mediators, such as IL-1 (Ben-Hur et al., 2003), IL-6 (Ekdahl et al., 2003), IFN- $\gamma$ (Butovsky et al., 2006), and TNF-alpha (Iosif et al., 2006; for review on this topic; see Sierra et al., 2014). In addition, in several pathophysiological conditions associated with inflammatory processes, activated inflammatory cells generate large amounts of reactive oxygen species such as superoxide, hydrogen peroxide and the hydroxyl

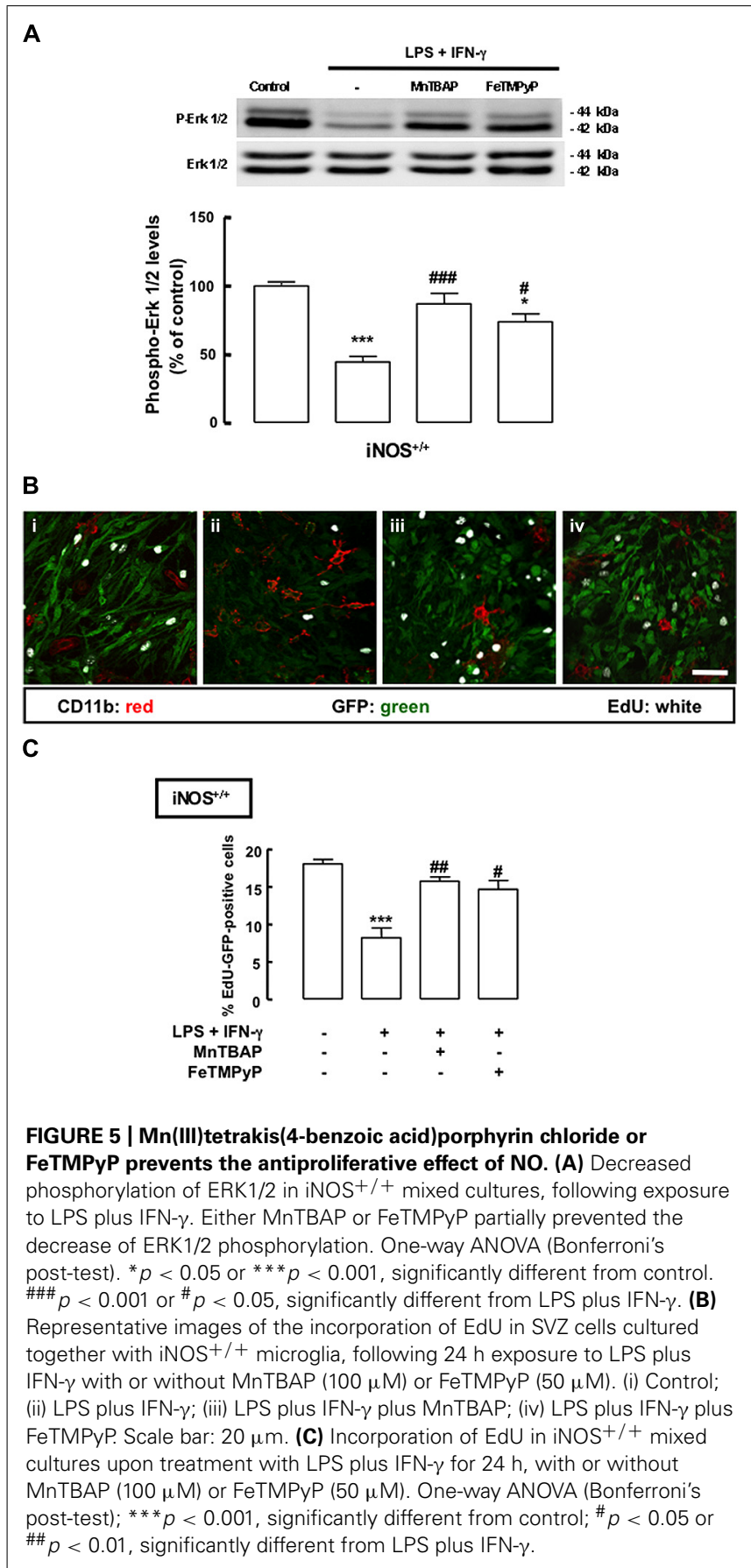

radical, concomitantly with increased iNOS expression and production of large amounts of NO. NO and superoxide readily react to form $\mathrm{ONOO}^{-}$, which is an extremely reactive molecule (Beckman and Crow, 1993; Ischiropoulos and al-Mehdi, 1995; Pryor and Squadrito, 1995; Radi et al., 2001), also making it very difficult to experimentally measure the production of superoxide in conditions where NO is present. Nitration is an irreversible chemical modification occurring in proteins that results from the reaction of $\mathrm{ONOO}^{-}$with amino acid residues, particularly tyrosine (Hanafy et al., 2001). Tyrosine nitration seriously affects 


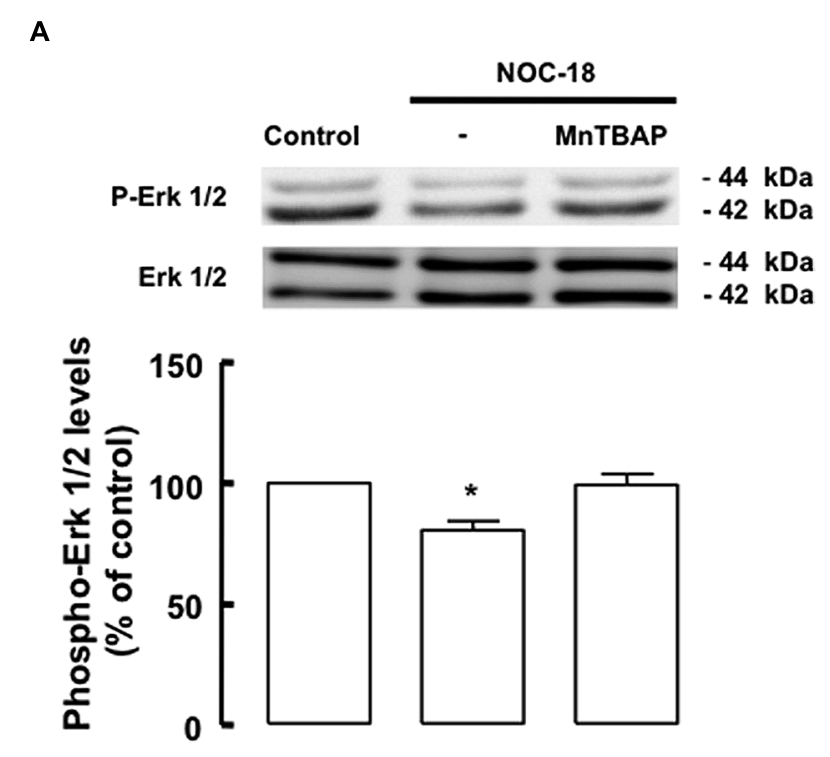

B

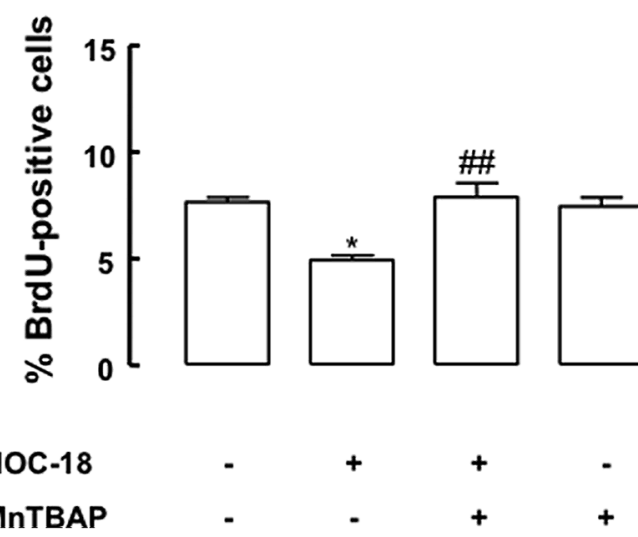

FIGURE 6 | High levels of NO decrease the activation of the ERK1/2 signaling pathway. (A) High levels of NOC-18 $(100 \mu \mathrm{M})$ decreased the phosphorylation of ERK1/2 in SVZ cell lysates. MnTBAP prevented the decrease of ERK1/2 phosphorylation. One-way ANOVA (Bonferroni's post-test). ${ }^{*} p<0.05$, significantly different from control. (B) MnTBAP $(100 \mu \mathrm{M})$ prevented the antiproliferative effect of NOC-18 $(100 \mu \mathrm{M})$ in SVZ cell cultures, as determined by BrdU incorporation. One-way ANOVA (Bonferroni's post-test). ${ }^{*} p<0.05$, significantly different from control. $\# \#<0.01$, significantly different from NOC-18.

tyrosine phosphorylation/dephosphorylation signaling cascades (Monteiro et al., 2008).

Indeed, in this work we also observed that exposure to a high concentration of $\mathrm{NO}$ caused the nitration of the EGF receptor in iNOS $^{+/+}$mixed cultures. We observed that the increased production of $\mathrm{NO}$ by iNOS ${ }^{+/+}$microglia triggered by treatment with LPS plus IFN- $\gamma$ is concomitant with increased nitration of the EGF receptor, which correlates with a decreased signaling through the ERK/MAPK pathway, leading to an antiproliferative effect on SVZ-derived NSCs. Moreover, lack of NO (by knockout of iNOS), prevented the nitration of the EGF receptor under inflammatory conditions. Indeed, in $\mathrm{iNOS}^{-/-}$mixed cultures, although there was activation of microglial cells following treatment with LPS plus IFN- $\gamma$, which was characterized by the presence of morphologic changes, no differences in cell proliferation were found when compared to untreated cultures. Several studies have shown that the pharmacological inhibition of inflammation triggered by injection of LPS (Monje et al., 2003), or experimentally induced seizures (Ekdahl et al., 2003), can restore hippocampal neurogenesis. However, some pro-inflammatory mediators, such as interleukin-6 (IL-6), released by activated microglia, seem to be important contributors to the inhibition of SGZ neurogenesis (Vallieres et al., 2002; Monje et al., 2003). On the other hand, microglia can also release trophic factors (Batchelor et al., 1999), like brain-derived neurotrophic factor (BDNF), that has been reported to promote neurogenesis (Benraiss et al., 2001). Thus, activated microglia may have a beneficial or detrimental role depending on the stimulus, and local and temporal environmental changes during a lesion to the nervous system (Kettenmann et al., 2011).

It should be noted that in mixed cultures cells are in close contact, therefore, it is very likely that in iNOS $+/+$ mixed cultures, NO levels achieved locally can be even higher, as evidenced by the increased nitration of the EGF receptor following acute stimulation of microglial cells with LPS plus IFN $-\gamma$. Moreover, we showed that scavenging nitrogen reactive species formation, by MnTBAP or FeTMPyP treatment (Misko et al., 1998; Salvemini et al., 1998), restored basal cell proliferation and nitration of the EGF receptor was prevented in iNOS ${ }^{+/+}$mixed cultures.

Our data further indicates that concomitantly with increased nitration in tyrosine residues of the EGF receptor, NO decreased the phosphorylation status of this receptor, possibly by inhibiting the tyrosine kinase activity of EGFR, which has over 15 tyrosine residues that can be phosphorylated and contribute to its activation. We demonstrate that nitration of tyrosine residues prevents the phosphorylation of such tyrosine residues in the EGF receptor, which is paramount for its activation and downstream signaling. In addition, MnTBAP or FeTMPyP prevented the decrease in the phosphorylation status of the EGF receptor in iNOS $^{+/+}$mixed cultures challenged with LPS plus IFN$\gamma$. Altogether, these evidences support our hypothesis that the antiproliferative effect of inflammation is mediated by NO production. NO from inflammatory origin is involved in the decreased activation of the ERK/MAPK pathway, which is mainly caused by the nitration of EGFR receptor, which compromises its phosphorylation and further signaling. Some studies have reported that NO can have an antiproliferative effect by affecting the phosphorylation of the EGF receptor in fibroblasts (Estrada et al., 1997), neuroblastoma cells (Murillo-Carretero et al., 2002, 2009), and NSCs (Torroglosa et al., 2007). In fact, in neuroblastoma cells, it was shown that NO inhibits the EGF receptor by $S$ nitrosylation (Murillo-Carretero et al., 2009), but the inhibitory effect of NO produced by microglia (via inducible NO synthase) in NSC proliferation was only now addressed in our study.

To our knowledge, this is the first study showing nitration of the EGF receptor as the main cause to the impairment of the signaling through the ERK/MAPK pathway, particularly under inflammatory conditions, which compromise proliferation of NSCs. In 
A
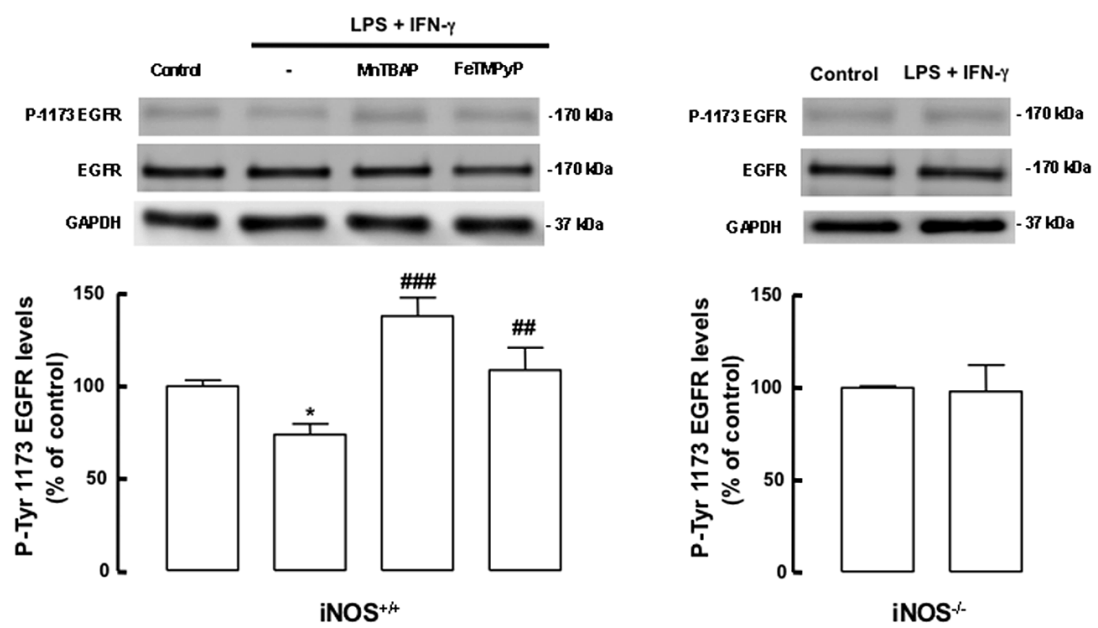

B

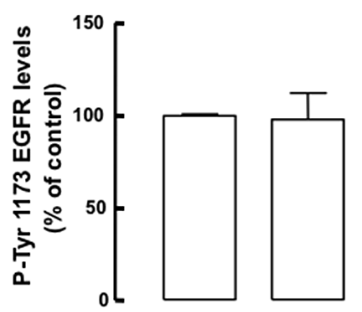

iNOS
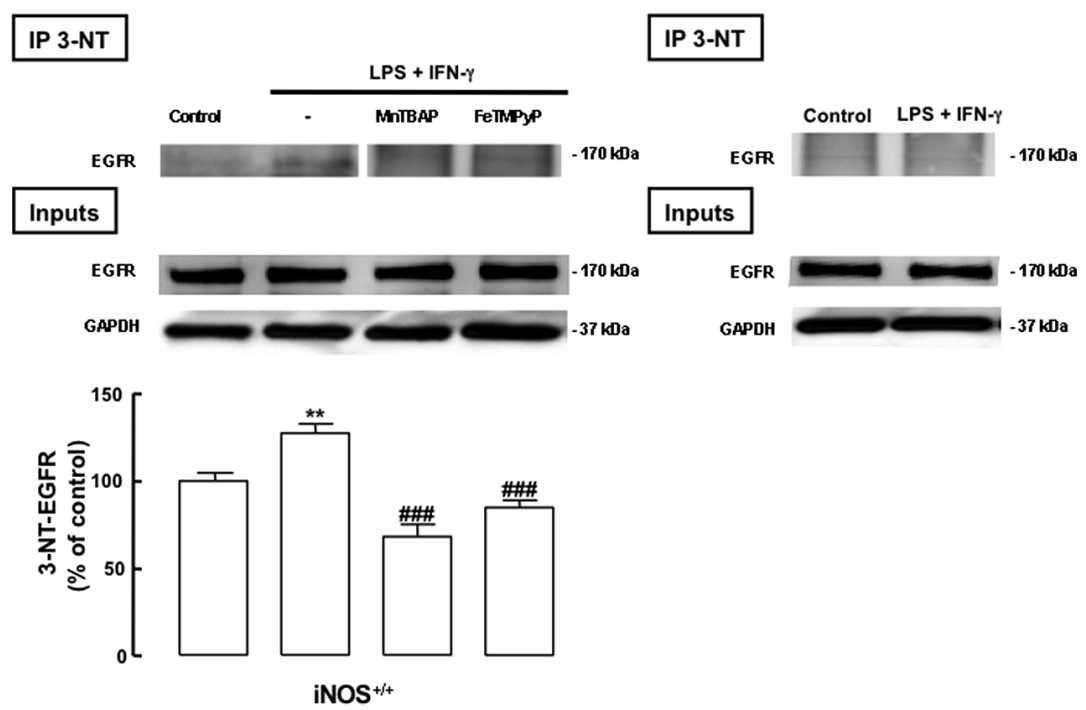

FIGURE 7 | Nitric oxide from inflammatory origin has an antiproliferative effect, via nitration and decreased phosphorylation of the EGF receptor, in iNOS $+/+$ mixed cultures. (A) Decreased phosphorylation of tyrosine residues (P-Tyr 1173) in iNOS $+/+$ mixed culture, but not in iNOS $-/-$ mixed culture lysates, following exposure to LPS plus IFN- $\gamma$. Both MnTBAP or FeTMPyP partially prevented the decrease of tyrosine phosphorylation in the EGFR. EGFR or GADPH were used as loading controls. One-way ANOVA (Bonferroni's post-test). ${ }^{*} p<0.05$, significantly different from Control. \#\#\# $p<0.001$ or

\#\# $p<0.01$, significantly different from LPS plus IFN- $\gamma$. Two-tailed $t$-test
(iNOS ${ }^{-1-}$ mixed culture); $p>0.05$. (B) Nitration of the EGFR in SVZ cells in mixed cultures with iNOS $+/+$ microglia, but not with iNOS $-1-$ microglia, following stimulation with LPS plus IFN- $\gamma$ for $24 \mathrm{~h}$. MnTBAP $(100 \mu \mathrm{M})$ and FeTMPyP $(50 \mu \mathrm{M})$ prevented the nitration of the EGFR in iNOS $^{+/+}$mixed cultures, following exposure to LPS plus IFN- $\gamma$ for $24 \mathrm{~h}$. Nitration was assessed by immunoblotting against the EGFR, after immunoprecipitation of the nitrated proteins (IP-3NT). EGFR or GAPDH were used as loading controls. One-way ANOVA (Bonferroni's post-test). ${ }^{* *} p<0.01$, significantly different from Control. \#\#\# $p<0.001$, significantly different from LPS plus IFN- $\gamma$.
Caco-2 cells (cell line obtained from human colon carcinoma), nitration of EGFR was first observed following the exposure to $\mathrm{ONOO}^{-}$(Uc etal., 2003). Several other players of the EGFR signaling cascade are also likely to be susceptible to nitration, since they also have tyrosine residues that participate in EGFR signaling by phosphorylation/dephosphorylation and may, thus, be nitrated and inactivated. Although we did not address these other players in this work, it cannot be excluded that other participants in proliferation signaling, other than the EGF receptor and downstream signaling cascades, can be affected by NO-mediated nitration, particularly in inflammatory conditions. Moreover, the antiproliferative effect of acute inflammatory conditions may be related to the enhancement of cell differentiation, where NO is likely to be a player. There is evidence showing that NO from inflammatory origin is involved in astrogliogenesis (Covacu et al., 2006; Bergsland etal., 2014), neurogenesis in the SVZ (Walton et al., 2006), or oligodendrogenesis (Kempermann and Neumann, 2003; Butovsky et al., 2006). 
In previous works by our group we reported that low levels of NO, although in the pathophysiological range, have a proliferative effect in SVZ-derived NSCs by targeting two pathways in a biphasic manner, initially mediated by the ERK/MAP kinase pathway (Carreira et al., 2010) and at later stages by the cGMP/PKG pathway (Carreira et al., 2012). In this work, we observed that higher levels of NO have an opposite effect by preventing regular proliferation signaling through the ERK/MAPK pathway through the nitration of the EGF receptor which caused a decrease in its phosphorylation. Although we did not test the effect of low dose of NO or contribution of cGMP/PKG in our mixed culture model, we cannot exclude a possible effect of high levels of $\mathrm{NO}$ in preventing regular signaling through this pathway, as already described by others in a pathological context both in vitro and in vivo (Zhang etal., 2002, 2012; for review on this topic; see Zhang et al., 2013). One of the mechanisms underlying NO toxicity in neurogenic niches includes $\mathrm{ONOO}^{-}$formation, an event that has been described in vivo after ischemic stroke (Keynes and Garthwaite, 2004).

Overall, our findings highlight that control of the nitrergic system may be an important target in cell transplantation techniques, particularly in the case of grafting of NSC in lesioned areas. Published evidence demonstrates that surviving grafts are influenced by the innate immune response, particularly due to acute microglia activation, which significantly impacts the survival and fate of both endogenous and transplanted neural progenitor cells (Monje et al., 2002, 2003; Ekdahl et al., 2003; Ormerod et al., 2008). In this context, this work highlights a mechanism that may be involved in the deleterious effect of inflammation in the viability of grafted NSCs, which is mediated by high levels of NO produced by microglia via iNOS.

Nevertheless, we show that it is possible to prevent the antiproliferative effects of microglia during an acute inflammatory response, by preventing the formation of nitrogen reactive species, with could be used as a strategy to improve the efficiency of transplantation techniques. Overall, our work sheds new light into the mechanisms underlying the effects of $\mathrm{NO}$ on the proliferation of NSCs, and may help in steering research efforts toward understanding how modulation of the nitrergic system can be used to regulate proliferation of stem cells in a regenerative context.

\section{AUTHOR CONTRIBUTIONS}

Maria I. Morte, Ana I. Santos, and Ana S. Lourenço contributed to conception and design of the work, acquisition, analysis and interpretation of data for the work, and drafting the manuscript. António F. Ambrósio has been involved in conception, analysis and interpretation of data, being also involved in drafting and revising the manuscript critically. Bruno P. Carreira, Caetana M. Carvalho, and Inês M. Araújo have been involved in the conception, design of the work, acquisition, analysis and interpretation of data, being also involved in drafting and revising the manuscript critically. All authors agree that all the questions related to the accuracy or integrity of the work have been appropriately investigated and resolved, giving final approval of the version to be published.

\section{ACKNOWLEDGMENTS}

This work was supported by the Foundation for Science and Technology, (FCT, Portugal), COMPETE and FEDER (grants PEst-C/SAU/LA0001/2013-2014, PEst-OE/EQB/LA0023/20132014, PTDC/SAU-NEU/102612/2008 and PTDC/NEU-OSD/0473/ 2012). Bruno P. Carreira, Maria I. Morte, Ana I. Santos, and Ana S. Lourenço were supported by FCT, Portugal (fellowships SFRH/BPD/78901/2011, SFRH/BD/38127/2007, SFRH/BD/77903/2011, and SFRH/BD/79308/2011).

\section{REFERENCES}

Alvarez-Buylla, A., Seri, B., and Doetsch, F. (2002). Identification of neural stem cells in the adult vertebrate brain. Brain Res. Bull. 57, 751-758. doi: 10.1016/S03619230(01)00770-5

Alvaro, A. R., Martins, J., Araujo, I. M., Rosmaninho-Salgado, J., Ambrosio, A. F., and Cavadas, C. (2008). Neuropeptide Y stimulates retinal neural cell proliferation involvement of nitric oxide. J. Neurochem. 105, 2501-2510. doi: 10.1111/j.14714159.2008.05334.x

Arvidsson, A., Collin, T., Kirik, D., Kokaia, Z., and Lindvall, O. (2002). Neuronal replacement from endogenous precursors in the adult brain after stroke. Nat. Med. 8, 963-970. doi: 10.1038/nm747

Bal-Price, A., and Brown, G. C. (2001). Inflammatory neurodegeneration mediated by nitric oxide from activated glia-inhibiting neuronal respiration, causing glutamate release and excitotoxicity. J. Neurosci. 21, 6480-6491.

Batchelor, P. E., Liberatore, G. T., Wong, J. Y., Porritt, M. J., Frerichs, F., Donnan, G. A., et al. (1999). Activated macrophages and microglia induce dopaminergic sprouting in the injured striatum and express brain-derived neurotrophic factor and glial cell line-derived neurotrophic factor. J. Neurosci. 19, 1708-1716.

Beckman, J. S., and Crow, J. P. (1993). Pathological implications of nitric oxide, superoxide and peroxynitrite formation. Biochem. Soc. Trans. 21, 330-334.

Beltran, B., Quintero, M., Garcia-Zaragoza, E., O’Connor, E., Esplugues, J. V., and Moncada, S. (2002). Inhibition of mitochondrial respiration by endogenous nitric oxide: a critical step in Fas signaling. Proc. Natl. Acad. Sci. U.S.A. 99, 8892-8897. doi: 10.1073/pnas.092259799092259799

Ben-Hur, T., Ben-Menachem, O., Furer, V., Einstein, O., Mizrachi-Kol, R., and Grigoriadis, N. (2003). Effects of proinflammatory cytokines on the growth, fate, and motility of multipotential neural precursor cells. Mol. Cell. Neurosci. 24, 623-631. doi: 10.1016/S1044-7431(03)00218-5

Benraiss, A., Chmielnicki, E., Lerner, K., Roh, D., and Goldman, S. A. (2001). Adenoviral brain-derived neurotrophic factor induces both neostriatal and olfactory neuronal recruitment from endogenous progenitor cells in the adult forebrain. $J$. Neurosci. 21, 6718-6731.

Bergsland, M., Covacu, R., Perez Estrada, C., Svensson, M., and Brundin, L. (2014). Nitric oxide-induced neuronal to glial lineage fate-change depends on NRSF/REST function in neural progenitor cells. Stem Cells 32, 2539-2549. doi: 10.1002/stem.1749

Boje, K. M., and Arora, P. K. (1992). Microglial-produced nitric oxide and reactive nitrogen oxides mediate neuronal cell death. Brain Res. 587, 250-256. doi: 10.1016/0006-8993(92)91004-X

Buck, S. B., Bradford, J., Gee, K. R., Agnew, B. J., Clarke, S. T., and Salic, A. (2008). Detection of S-phase cell cycle progression using 5-ethynyl-2'-deoxyuridine incorporation with click chemistry, an alternative to using 5-bromo-2' deoxyuridine antibodies. Biotechniques 44, 927-929. doi: 10.2144/000112812

Butovsky, O., Ziv, Y., Schwartz, A., Landa, G., Talpalar, A. E., Pluchino, S., et al. (2006). Microglia activated by IL-4 or IFN-gamma differentially induce neurogenesis and oligodendrogenesis from adult stem/progenitor cells. Mol. Cell. Neurosci. 31, 149-160. doi: 10.1016/j.mcn.2005.10.006

Cacci, E., Ajmone-Cat, M. A., Anelli, T., Biagioni, S., and Minghetti, L. (2008). In vitro neuronal and glial differentiation from embryonic or adult neural precursor cells are differently affected by chronic or acute activation of microglia. Glia 56, 412-425. doi: 10.1002/glia.20616

Calabrese, V., Cornelius, C., Rizzarelli, E., Owen, J. B., Dinkova-Kostova, A. T., and Butterfield, D. A. (2009). Nitric oxide in cell survival: a janus molecule. Antioxid. Redox Signal. 11, 2717-2739. doi: 10.1089/ARS.2009.2721

Calabrese, V., Mancuso, C., Calvani, M., Rizzarelli, E., Butterfield, D. A., and Stella, A. M. (2007). Nitric oxide in the central nervous system: neuroprotection versus neurotoxicity. Nat. Rev. Neurosci. 8, 766-775. doi: 10.1038/nrn2214 
Cappella, P., Gasparri, F., Pulici, M., and Moll, J. (2008). A novel method based on click chemistry, which overcomes limitations of cell cycle analysis by classical determination of BrdU incorporation, allowing multiplex antibody staining. Cytometry A 73, 626-636. doi: 10.1002/cyto.a.20582

Carreira, B. P., Morte, M. I., Inacio, A., Costa, G., Rosmaninho-Salgado, J., Agasse F., et al. (2010). Nitric oxide stimulates the proliferation of neural stem cells bypassing the epidermal growth factor receptor. Stem Cells 28, 1219-1230. doi: $10.1002 /$ stem.444

Carreira, B. P., Morte, M. I., Lourenco, A. S., Santos, A. I., Inacio, A., Ambrosio, A. F., et al. (2012). Differential contribution of the guanylyl cyclase-cyclic GMPprotein kinase $\mathrm{G}$ pathway to the proliferation of neural stem cells stimulated by nitric oxide. Neurosignals 21, 1-13. doi: 10.1159/000332811

Chao, C. C., Hu, S., Molitor, T. W., Shaskan, E. G., and Peterson, P. K. (1992) Activated microglia mediate neuronal cell injury via a nitric oxide mechanism. J. Immunol. 149, 2736-2741.

Chehrehasa, F., Meedeniya, A. C., Dwyer, P., Abrahamsen, G., and MackaySim, A. (2009). EdU, a new thymidine analogue for labelling proliferating cells in the nervous system. J. Neurosci. Methods 177, 122-130. doi: 10.1016/j.jneumeth.2008.10.006

Covacu, R., Danilov, A. I., Rasmussen, B. S., Hallen, K., Moe, M. C., Lobell, A., et al. (2006). Nitric oxide exposure diverts neural stem cell fate from neurogenesis towards astrogliogenesis. Stem Cells 24, 2792-2800. doi: 10.1634/stemcells.20050640

Curtis, M. A., Eriksson, P. S., and Faull, R. L. (2007). Progenitor cells and adult neurogenesis in neurodegenerative diseases and injuries of the basal ganglia. Clin. Exp. Pharmacol. Physiol. 34, 528-532. doi: 10.1111/j.1440-1681.2007.04609.x

Davalos, D., Grutzendler, J., Yang, G., Kim, J. V., Zuo, Y., Jung, S., et al. (2005). ATP mediates rapid microglial response to local brain injury in vivo. Nat. Neurosci. 8 , 752-758. doi: 10.1038/nn1472

Dawson, V. L., Brahmbhatt, H. P., Mong, J. A., and Dawson, T. M. (1994). Expression of inducible nitric oxide synthase causes delayed neurotoxicity in primary mixed neuronal-glial cortical cultures. Neuropharmacology 33, 1425-1430. doi: 10.1016/0028-3908(94)90045-0

Dawson, V. L., Dawson, T. M., Bartley, D. A., Uhl, G. R., and Snyder, S. H. (1993) Mechanisms of nitric oxide-mediated neurotoxicity in primary brain cultures J. Neurosci. 13, 2651-2661.

Doetsch, F., Petreanu, L., Caille, I., Garcia-Verdugo, J. M., and Alvarez-Buylla A. (2002). EGF converts transit-amplifying neurogenic precursors in the adult brain into multipotent stem cells. Neuron 36, 1021-1034. doi: 10.1016/S08966273(02)01133-9

Ekdahl, C. T., Claasen, J. H., Bonde, S., Kokaia, Z., and Lindvall, O. (2003). Inflammation is detrimental for neurogenesis in adult brain. Proc. Natl. Acad. Sci. U.S.A. 100, 13632-13637. doi: 10.1073/pnas.22340311002234031100

Ekdahl, C. T., Kokaia, Z., and Lindvall, O. (2009). Brain inflammation and adult neurogenesis: the dual role of microglia. Neuroscience 158, 1021-1029. doi: 10.1016/j.neuroscience.2008.06.052

Eriksson, P. S., Perfilieva, E., Bjork-Eriksson, T., Alborn, A. M., Nordborg, C., Peterson, D. A., et al. (1998). Neurogenesis in the adult human hippocampus. Nat. Med. 4, 1313-1317. doi: 10.1038/3305

Estrada, C., Gomez, C., Martin-Nieto, J., De Frutos, T., Jimenez, A., and Villalobo, A. (1997). Nitric oxide reversibly inhibits the epidermal growth factor receptor tyrosine kinase. Biochem. J. 326(Pt 2), 369-376.

Gage, F. H. (2000). Mammalian neural stem cells. Science 287, 1433-1438. doi: $10.1126 /$ science.287.5457.1433

Galea, E., Feinstein, D. L., and Reis, D. J. (1992). Induction of calcium-independent nitric oxide synthase activity in primary rat glial cultures. Proc. Natl. Acad. Sci. U.S.A. 89, 10945-10949. doi: 10.1073/pnas.89.22.10945

Giulian, D., and Baker, T. J. (1986). Characterization of ameboid microglia isolated from developing mammalian brain. J. Neurosci. 6, 2163-2178.

Green, L. C., Wagner, D. A., Glogowski, J., Skipper, P. L., Wishnok, J. S., and Tannenbaum, S. R. (1982). Analysis of nitrate, nitrite, and $[15 \mathrm{~N}]$ nitrate in biological fluids. Anal. Biochem. 126, 131-138. doi: 10.1016/0003-2697(82) 90118-X

Guix, F. X., Uribesalgo, I., Coma, M., and Munoz, F. J. (2005). The physiology and pathophysiology of nitric oxide in the brain. Prog. Neurobiol. 76, 126-152. doi: 10.1016/j.pneurobio.2005.06.001

Hanafy, K. A., Krumenacker, J. S., and Murad, F. (2001). NO, nitrotyrosine, and cyclic GMP in signal transduction. Med. Sci. Monit. 7, 801-819.
Ignarro, L. J. (2000). The unique role of nitric oxide as a signaling molecule in the cardiovascular system. Ital. Heart J. 1(Suppl. 3), S28-S29.

Iosif, R. E., Ekdahl, C. T., Ahlenius, H., Pronk, C. J., Bonde, S., Kokaia, Z., et al. (2006). Tumor necrosis factor receptor 1 is a negative regulator of progenitor proliferation in adult hippocampal neurogenesis. J. Neurosci. 26, 9703-9712. doi: 10.1523/JNEUROSCI.2723-06.2006

Ischiropoulos, H., and al-Mehdi, A. B. (1995). Peroxynitrite-mediated oxidative protein modifications. FEBS Lett. 364, 279-282. doi: 10.1016/0014-5793(95)00307-U

Keefer, L. K., Nims, R. W., Davies, K. M., and Wink, D. A. (1996). "NONOates" (1-substituted diazen-1-ium-1,2-diolates) as nitric oxide donors: convenient nitric oxide dosage forms. Methods Enzymol. 268, 281-293. doi: 10.1016/S00766879(96)68030-6

Kempermann, G., and Neumann, H. (2003). Neuroscience. Microglia: the enemy within? Science 302, 1689-1690. doi: 10.1126/science.1092864302/5651/1689

Kettenmann, H., Hanisch, U. K., Noda, M., and Verkhratsky, A. (2011). Physiology of microglia. Physiol. Rev. 91, 461-553. doi: 10.1152/physrev.00011.2010

Keynes, R. G., and Garthwaite, J. (2004). Nitric oxide and its role in ischaemic brain injury. Curr. Mol. Med. 4, 179-191. doi: 10.2174/1566524043479176

Lane, P., and Gross, S. S. (1999). Cell signaling by nitric oxide. Semin. Nephrol. 19, 215-229.

Lowenstein, D. H., and Parent, J. M. (1999). Brain, heal thyself. Science 283, 11261127. doi: $10.1126 /$ science.283.5405.1126

Madhusoodanan, K. S., and Murad, F. (2007). NO-cGMP signaling and regenerative medicine involving stem cells. Neurochem. Res. 32, 681-694. doi: 10.1007/s11064006-9167-y

Matarredona, E. R., Murillo-Carretero, M., Moreno-Lopez, B., and Estrada, C. (2005). Role of nitric oxide in subventricular zone neurogenesis. Brain Res. Brain Res. Rev. 49, 355-366. doi: 10.1016/j.brainresrev.2005.01.001

Ming, G. L., and Song, H. (2011). Adult neurogenesis in the mammalian brain: significant answers and significant questions. Neuron 70, 687-702. doi: 10.1016/j.neuron.2011.05.001

Misko, T. P., Highkin, M. K., Veenhuizen, A. W., Manning, P. T., Stern, M. K., Currie, M. G., et al. (1998). Characterization of the cytoprotective action of peroxynitrite decomposition catalysts. J. Biol. Chem. 273, 15646-15653. doi: 10.1074/jbc.273.25.15646

Moncada, S., and Bolanos, J. P. (2006). Nitric oxide, cell bioenergetics and neurodegeneration. J. Neurochem. 97, 1676-1689. doi: 10.1111/j.1471-4159.2006.03988.x

Monje, M. L., Mizumatsu, S., Fike, J. R., and Palmer, T. D. (2002). Irradiation induces neural precursor-cell dysfunction. Nat. Med. 8, 955-962. doi: 10.1038/nm749

Monje, M. L., Toda, H., and Palmer, T. D. (2003). Inflammatory blockade restores adult hippocampal neurogenesis. Science 302, 1760-1765. doi: 10.1126/science. 10884171088417

Monteiro, H. P., Arai, R. J., and Travassos, L. R. (2008). Protein tyrosine phosphorylation and protein tyrosine nitration in redox signaling. Antioxid. Redox Signal. 10, 843-889. doi: 10.1089/ars.2007.1853

Moreno-Lopez, B., Romero-Grimaldi, C., Noval, J. A., Murillo-Carretero, M., Matarredona, E. R., and Estrada, C. (2004). Nitric oxide is a physiological inhibitor of neurogenesis in the adult mouse subventricular zone and olfactory bulb. J. Neurosci. 24, 85-95. doi: 10.1523/JNEUROSCI.1574-03.200424/1/85

Murillo-Carretero, M., Ruano, M. J., Matarredona, E. R., Villalobo, A., and Estrada, C. (2002). Antiproliferative effect of nitric oxide on epidermal growth factor-responsive human neuroblastoma cells. J. Neurochem. 83, 119-131. doi: 10.1046/j.1471-4159.2002.01116.x

Murillo-Carretero, M., Torroglosa, A., Castro, C., Villalobo, A., and Estrada, C. (2009). S-Nitrosylation of the epidermal growth factor receptor: a regulatory mechanism of receptor tyrosine kinase activity. Free Radic. Biol. Med. 46, 471-479. doi: 10.1016/j.freeradbiomed.2008.10.048

Murphy, S. (2000). Production of nitric oxide by glial cells: regulation and potential roles in the CNS. Glia 29, 1-13. doi: 10.1002/(SICI)10981136(20000101)29:1<1::AID-GLIA1 > 3.0.CO;2-N

Nathan, C., and Xie, Q. W. (1994). Nitric oxide synthases: roles, tolls, and controls. Cell 78, 915-918. doi: 10.1016/0092-8674(94)90266-6

Nimmerjahn, A., Kirchhoff, F., and Helmchen, F. (2005). Resting microglial cells are highly dynamic surveillants of brain parenchyma in vivo. Science 308, 1314-1318. doi: 10.1126/science.1110647

Ormerod, B. K., Palmer, T. D., and Caldwell, M. A. (2008). Neurodegeneration and cell replacement. Philos. Trans. R. Soc. Lond. B Biol. Sci. 363, 153-170. doi: 10.1098/rstb.2006.2018 
Packer, M. A., Stasiv, Y., Benraiss, A., Chmielnicki, E., Grinberg, A., Westphal, H., etal. (2003). Nitric oxide negatively regulates mammalian adult neurogenesis. Proc. Natl. Acad. Sci. U.S.A. 100, 9566-9571. doi: 10.1073/pnas.16335791001633579100

Parent, J. M., Yu, T. W., Leibowitz, R. T., Geschwind, D. H., Sloviter, R. S., and Lowenstein, D. H. (1997). Dentate granule cell neurogenesis is increased by seizures and contributes to aberrant network reorganization in the adult rat hippocampus. J. Neurosci. 17, 3727-3738.

Pryor, W. A., and Squadrito, G. L. (1995). The chemistry of peroxynitrite: a product from the reaction of nitric oxide with superoxide. Am. J. Physiol. 268, L699-L722.

Radi, R., Peluffo, G., Alvarez, M. N., Naviliat, M., and Cayota, A. (2001). Unraveling peroxynitrite formation in biological systems. Free Radic. Biol. Med. 30, 463-488. doi: 10.1016/S0891-5849(00)00373-7

Reynolds, B. A., and Weiss, S. (1996). Clonal and population analyses demonstrate that an EGF-responsive mammalian embryonic CNS precursor is a stem cell. Dev. Biol. 175, 1-13. doi: 10.1006/dbio.1996.0090

Rock, R. B., Gekker, G., Hu, S., Sheng, W. S., Cheeran, M., Lokensgard, J. R., et al. (2004). Role of microglia in central nervous system infections. Clin. Microbiol. Rev. 17, 942-964, table of contents. doi: 10.1128/CMR.17.4.942-96 4.2004

Salvemini, D., Wang, Z. Q., Stern, M. K., Currie, M. G., and Misko, T. P. (1998). Peroxynitrite decomposition catalysts: therapeutics for peroxynitritemediated pathology. Proc. Natl. Acad. Sci. U.S.A. 95, 2659-2663. doi: 10.1073/pnas.95.5.2659

Saura, J., Tusell, J. M., and Serratosa, J. (2003). High-yield isolation of murine microglia by mild trypsinization. Glia 44, 183-189. doi: 10.1002/glia. 10274

Sierra, A., Beccari, S., Diaz-Aparicio, I., Encinas, J. M., Comeau, S., and Tremblay, M. E. (2014). Surveillance, phagocytosis, and inflammation: how never-resting microglia influence adult hippocampal neurogenesis. Neural Plast. 2014, 610343. doi: $10.1155 / 2014 / 610343$

Szabo, C., Day, B. J., and Salzman, A. L. (1996). Evaluation of the relative contribution of nitric oxide and peroxynitrite to the suppression of mitochondrial respiration in immunostimulated macrophages using a manganese mesoporphyrin superoxide dismutase mimetic and peroxynitrite scavenger. FEBS Lett. 381, 82-86. doi: 10.1016/0014-5793(96)00087-7

Taupin, P. (2005). Adult neurogenesis in the mammalian central nervous system: functionality and potential clinical interest. Med. Sci. Monit. 11, RA247-RA252.
Torroglosa, A., Murillo-Carretero, M., Romero-Grimaldi, C., Matarredona, E. R., Campos-Caro, A., and Estrada, C. (2007). Nitric oxide decreases subventricular zone stem cell proliferation by inhibition of epidermal growth factor receptor and phosphoinositide-3-kinase/Akt pathway. Stem Cells 25, 88-97. doi: 10.1634/stemcells.2006-0131

Uc, A., Kooy, N. W., Conklin, J. L., and Bishop, W. P. (2003). Peroxynitrite inhibits epidermal growth factor receptor signaling in Caco-2 cells. Dig. Dis. Sci. 48, 2353-2359. doi: 10.1023/B:DDAS.0000007874.20403.1d

Vallieres, L., Campbell, I. L., Gage, F. H., and Sawchenko, P. E. (2002). Reduced hippocampal neurogenesis in adult transgenic mice with chronic astrocytic production of interleukin-6. J. Neurosci. 22, 486-492.

Walton, N. M., Sutter, B. M., Laywell, E. D., Levkoff, L. H., Kearns, S. M., Marshall, G. P. II, et al. (2006). Microglia instruct subventricular zone neurogenesis. Glia 54, 815-825. doi: 10.1002/glia.20419

Zhang, R., Wang, Y., Zhang, L., Zhang, Z., Tsang, W., Lu, M., et al. (2002). Sildenafil (Viagra) induces neurogenesis and promotes functional recovery after stroke in rats. Stroke 33, 2675-2680. doi: 10.1161/01.STR.0000034399.95249.59

Zhang, R. L., Chopp, M., Roberts, C., Wei, M., Wang, X., Liu, X., et al. (2012). Sildenafil enhances neurogenesis and oligodendrogenesis in ischemic brain of middle-aged mouse. PLoS ONE 7:e48141. doi: 10.1371/journal.pone.0048141

Zhang, R. L., Zhang, Z. G., and Chopp, M. (2013). Targeting nitric oxide in the subacute restorative treatment of ischemic stroke. Expert Opin. Investig. Drugs 22, 843-851. doi: 10.1517/13543784.2013.793672

Conflict of Interest Statement: The authors declare that the research was conducted in the absence of any commercial or financial relationships that could be construed as a potential conflict of interest.

Received: 01 July 2014; accepted: 05 October 2014; published online: 28 October 2014. Citation: Carreira BP, Morte MI, Santos AI, Lourenço AS, Ambrósio AF, Carvalho CM and Araújo IM (2014) Nitric oxide from inflammatory origin impairs neural stem cell proliferation by inhibiting epidermal growth factor receptor signaling. Front. Cell. Neurosci. 8:343. doi: 10.3389/fncel.2014.00343

This article was submitted to the journal Frontiers in Cellular Neuroscience. Copyright $\odot 2014$ Carreira, Morte, Santos, Lourenço, Ambrósio, Carvalho and Araújo This is an open-access article distributed under the terms of the Creative Commons Attribution License (CC BY). The use, distribution or reproduction in other forums is permitted, provided the original author(s) or licensor are credited and that the original publication in this journal is cited, in accordance with accepted academic practice. No use, distribution or reproduction is permitted which does not comply with these terms. 